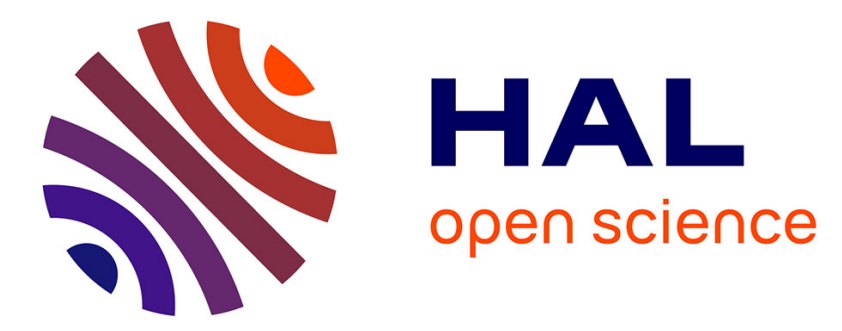

\title{
Two-step cycling process alternating implantation and remote plasma etching for topographically selective etching: Application to Si 3 N 4 spacer etching
}

Vincent Renaud, Camille Petit-Etienne, Jean-Paul Barnes, Jérémie Bisserier, Olivier Joubert, Erwine Pargon

\section{To cite this version:}

Vincent Renaud, Camille Petit-Etienne, Jean-Paul Barnes, Jérémie Bisserier, Olivier Joubert, et al.. Two-step cycling process alternating implantation and remote plasma etching for topographically selective etching: Application to Si 3 N 4 spacer etching. Journal of Applied Physics, 2019, 126 (24), pp.243301. 10.1063/1.5131030 . halshs-02428534

\section{HAL Id: halshs-02428534 \\ https://shs.hal.science/halshs-02428534}

Submitted on 6 Nov 2020

HAL is a multi-disciplinary open access archive for the deposit and dissemination of scientific research documents, whether they are published or not. The documents may come from teaching and research institutions in France or abroad, or from public or private research centers.
L'archive ouverte pluridisciplinaire HAL, est destinée au dépôt et à la diffusion de documents scientifiques de niveau recherche, publiés ou non, émanant des établissements d'enseignement et de recherche français ou étrangers, des laboratoires publics ou privés. 
Two-step cycling process alternating implantation and remote plasma etching for topographically selective etching: Application to $\mathrm{Si}_{3} \mathrm{~N}_{4}$ spacer etching

Cite as: J. Appl. Phys. 126, 243301 (2019); https://doi.org/10.1063/1.5131030

Submitted: 08 October 2019 . Accepted: 05 December 2019 . Published Online: 23 December 2019

Vincent Renaud, (D) Camille Petit-Etienne, Jean-Paul Barnes, Jérémie Bisserier, Olivier Joubert, and Erwine Pargon

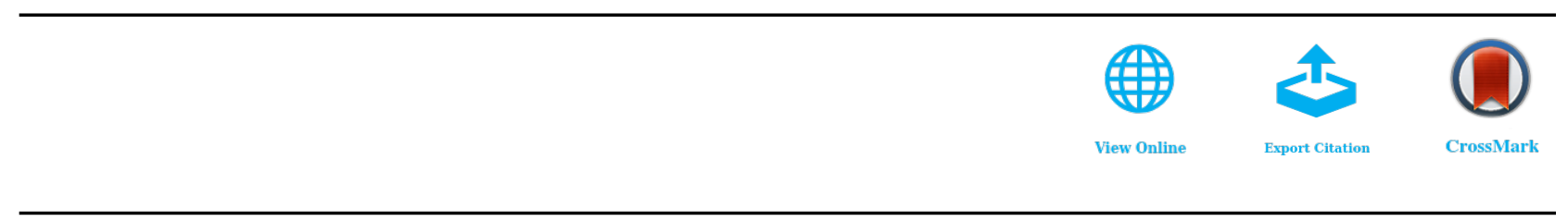

\section{ARTICLES YOU MAY BE INTERESTED IN}

Thin layer etching of silicon nitride: A comprehensive study of selective removal using $\mathrm{NH}_{3} /$

$\mathrm{NF}_{3}$ remote plasma

Journal of Vacuum Science \& Technology A 34, 061301 (2016); https://

doi.org/10.1116/1.4963072

\section{Overview of atomic layer etching in the semiconductor industry}

Journal of Vacuum Science \& Technology A 33, 020802 (2015); https://

doi.org/10.1116/1.4913379

Fluorocarbon based atomic layer etching of $\mathrm{Si}_{3} \mathrm{~N}_{4}$ and etching selectivity of $\mathrm{SiO}_{2}$ over $\mathrm{Si}_{3} \mathrm{~N}_{4}$

Journal of Vacuum Science \& Technology A 34, 041307 (2016); https://

doi.org/10.1116/1.4954961

\section{Meet the Next Generation of Quantum Analyzers And Join the Launch Event on November 17th}

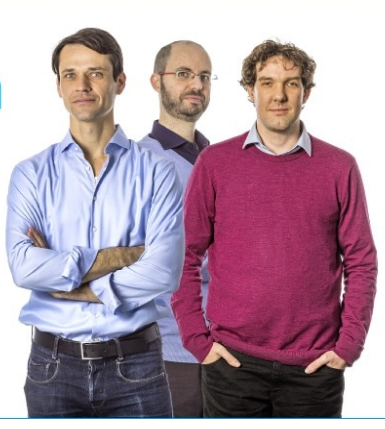




\title{
Two-step cycling process alternating implantation and remote plasma etching for topographically selective etching: Application to $\mathrm{Si}_{3} \mathrm{~N}_{4}$ spacer etching
}

\author{
Cite as: J. Appl. Phys. 126, 243301 (2019); doi: 10.1063/1.5131030 \\ Submitted: 8 October 2019 . Accepted: 5 December 2019 . \\ Published Online: 23 December 2019 \\ and Erwine Pargon ${ }^{1, a)}$ \\ AFFILIATIONS \\ ${ }^{1}$ Univ. Grenoble Alpes, CNRS, CEA/LETI Minatec, LTM, 38000 Grenoble, France \\ ${ }^{2}$ Univ. Grenoble Alpes, CEA/LETI Minatec, 38000 Grenoble, France \\ ${ }^{3}$ Applied Materials France, 864 chemin des Fontaines, 38190 Bernin, France
}

Vincent Renaud, ${ }^{7}$ Camille Petit-Etienne, ${ }^{1}$ (D) Jean-Paul Barnes, ${ }^{2}$ Jérémie Bisserier, ${ }^{3}$ Olivier Joubert, ${ }^{7}$

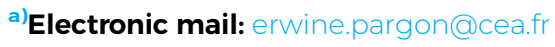

\begin{abstract}
This article proposes an original method to achieve topographically selective etching. It relies on cycling a two-step process comprising a plasma implantation step and a removal etching step using remote plasma source process. Both steps can be achieved in the same reactor prototype chamber, which has the capability to produce both capacitively coupled plasma and remote plasma (RP) discharges. It is shown that in RP processes, an incubation time exists before the etching starts. The introduction of a plasma implantation step prior to the RP step allows us to selectively functionalize the horizontal surfaces of the material with respect to the vertical surfaces, thanks to the ion directionality. The modifications induced by the implantation allow us to modify the incubation time between an implanted and a nonimplanted material offering a process window with infinite etch selectivity between horizontal and vertical surfaces. This approach has been demonstrated on $\mathrm{Si}_{3} \mathrm{~N}_{4}$ blanket films with the perspective to be applied to the $\mathrm{Si}_{3} \mathrm{~N}_{4}$ spacer etching process in which etch selectivity is a key issue. For this particular application, a cycling process comprising an $\mathrm{H}_{2}$ plasma implantation and a $\mathrm{He} / \mathrm{NH}_{3} / \mathrm{NF}_{3}$ remote plasma process has been developed. The $\mathrm{H}_{2}$ implantation modifies the $\mathrm{Si}_{3} \mathrm{~N}_{4}$ surface state by incorporating oxygen contaminants coming from the reactor wall and creating dangling bonds. This surface functionalization considerably reduces the incubation time. New insights into the etching mechanisms of $\mathrm{Si}_{3} \mathrm{~N}_{4}$ films exposed to $\mathrm{NH}_{3} / \mathrm{NF}_{3}$ remote plasma are proposed and explain why the presence of Si-O bonds is mandatory for the initiation of the etching.
\end{abstract}

Published under license by AIP Publishing. https://doi.org/10.1063/1.5131030

\section{INTRODUCTION}

The increasing complexity in fabricating devices consisting of various layers of nanoscale materials, and 3D features have led to the need for processing materials in a selective manner. ${ }^{1}$ Past few years, both academia and industry are looking for new process technologies allowing us to make atomic scale processing techniques, such as atomic layer deposition (ALD) and atomic layer etching (ALE), more selective., ${ }^{2,3}$ Similar to the growing field of selective area deposition, ${ }^{4,5}$ etch selectivity could be classified into two categories: area selective chemical etching and topographically selective etching. In the first case, the etch selectivity arises from a difference in the chemical affinity of the reactive neutrals with the present materials and with no preferential etching direction. In the second case, it refers to the ability to etch a material selectively with respect to itself in a preferential direction, i.e., etch the horizontal surfaces of a material selectively over vertical surfaces or vice versa.

In particular, the silicon nitride spacer etching process, which is considered one of the most challenging steps of Metal-OxideSemiconductor (MOS) transistor fabrication technologies, requires 
these two kinds of selectivities. On the one hand, the spacer process must enable the $\mathrm{Si}_{3} \mathrm{~N}_{4}$ spacer removal on horizontal surfaces (top and bottom of the pattern) without consuming the spacer sidewalls (vertical surfaces), and this is a very anisotropic way to generate straight spacer profiles. On the other hand, it must provide an extremely high chemical etch selectivity over the underneath silicon or silicon germanium in order to minimize the consumption of these materials in the source/drain regions. Minimizing the silicon recess and ion-induced damages to silicon surfaces are key criteria to ensure a high surface quality for the subsequent step of silicon or SiGe epitaxy.

Conventional plasma etching techniques based on $\mathrm{CHF}_{3} / \mathrm{O}_{2}$ continuous wave $(\mathrm{CW})$ plasma $^{6,7}$ showed some intrinsic limitations to remove silicon nitride on horizontal surfaces without inducing either critical dimension loss or $\mathrm{Si} / \mathrm{SiGe}$ source/drain recess. $^{8}$ Indeed, the ion-neutral synergy that drives the etching mechanism in CW plasma induces the creation of a few-nanometer-thick reactive layers (ion energies $>15-20 \mathrm{eV}$ ), which compromise the etch precision. ${ }^{9}$ Blanc et al. showed that improved spacer process performance can be obtained by using synchronous pulsed plasma technology. ${ }^{10}$ The switching on and off in a synchronous manner of both the source and bias powers at a low duty cycle allows us to decrease the average ion energy and the plasma chemical reactivity (more molecular than atomic), which ultimately reduce plasma induced damage. Although they showed that pulsed plasma process leads to minimized silicon recess and improved spacer profiles compared to CW plasma processes, the spacer process performance is still not satisfactory for advanced technology nodes. ${ }^{11,12}$

More recently, Posseme et al. proposed an interesting approach for the etching of a silicon nitride spacer with anisotropic sidewalls and minimal induced damage. ${ }^{13}$ This process, called "smart etch" hereafter, consists of two sequential steps. ${ }^{14}$ In the first step, the $\mathrm{Si}_{3} \mathrm{~N}_{4}$ film is anisotropically modified by a light ion implantation (typically $\mathrm{H}_{2}$ or $\mathrm{He}$ ) achieved either in an inductively coupled plasma (ICP) or capacitive coupled plasma (CCP) reactor. The layer modification depth is driven by the ion energy, while its chemical composition is determined by the ion dose. ${ }^{14}$ In a second step, the modified layer can be selectively removed by using an HF reactant either in a liquid solution ${ }^{14}$ or in gas phase (followed by water rinsing) ${ }^{15,16}$ or by using $\mathrm{NH}_{3} / \mathrm{NF}_{3} / \mathrm{He}$ remote plasmas (RPs) followed by an annealing step. ${ }^{17}$ For all these removal techniques, the etching of the modified $\mathrm{Si}_{3} \mathrm{~N}_{4}$ layer proceeds with the formation of ammonium hexafluorosilicate salts $\left[\left(\mathrm{NH}_{4}\right)_{2} \mathrm{SiF}_{6}\right]^{15-18}$ that are subsequently either dissolved in water (when HF is used) or outgassed by annealing (when $\mathrm{NH}_{3} / \mathrm{NF}_{3}$ remote plasma is used). Posseme et al. showed that removal with liquid $\mathrm{HF}$ and with $\mathrm{NH}_{3} /$ $\mathrm{NF}_{3}$ remote plasma has one major weakness in that it does not provide any selectivity to silicon dioxide. ${ }^{14,17}$ On the contrary, gaseous $\mathrm{HF}$ removal can provide a high selectivity between modified $\mathrm{Si}_{3} \mathrm{~N}_{4}$ and $\mathrm{SiO}_{2}$ but faces some queue time issues between the gaseous HF exposure and the aqueous phase removal. ${ }^{15,16} \mathrm{~A}$ too long queue time between those two steps leads to some residues that are difficult to remove. Moreover, in all the approaches proposed by Posseme et al., the two-step process requires at least the use of two different and separated equipment, implying an air exposure between the two steps. Another drawback is that the implantation step must be well calibrated to modify in one shot the targeted thickness to be etched. Cycles of the two steps could be envisaged to solve this issue, but it will require back and forth between the implantation reactor and the equipment used to remove the modified layer, compromising the process throughput. Sherpa et al. ${ }^{19,20}$ proposed to cycle the two steps in the same capacitive plasma reactor. $\mathrm{H}_{2}$ plasma at 20 mTorr was used for the implantation step, while fluorinated plasma such as $\mathrm{NF}_{3}$ or $\mathrm{SF}_{6}$ at high pressure ( $>500 \mathrm{mTorr}$ ) was proposed for the selective removal step. By operating the second step at high pressure, they expected to lower ion to neutral flux ratio and to minimize the ionic bombardment in order to favor a chemical and selective type of etching. In their case, the etching of the silicon nitride films during the second step does not proceed with the formation of a salt layer but is mainly driven by the chemical reactivity of atomic fluorine with $\mathrm{SiN}, \mathrm{SiH}$, or $\mathrm{NH}$ bonds based on thermodynamical considerations. Using this approach, they showed that the etch rate of the $\mathrm{H}_{2}$ implanted silicon nitride increases almost tenfold compared to the etch rate of pristine silicon nitride in the fluorinated plasma. They also mentioned that the etch selectivity to silicon oxide is superior to 100 , confirming the negligible role of ionized species in the fluorinated capacitive discharge at 500 mTorr. However, although not discussed in their article, we suspect that the process will not be selective over silicon if indeed the mechanisms are driven by atomic fluorine.

In this article, we propose a new route to implement the smart etch concept by cycling the two steps of the process in the same plasma reactor chamber that has the capability to produce both a CCP discharge for the implantation step and a remote plasma discharge in which only neutral species are involved for the removal step.

In Sec. II of this article, the experimental setup and characterization techniques will be described. The experimental results will be presented and discussed in Sec. III as follows. First, in Sec. III A, the modifications induced in a $\mathrm{Si}_{3} \mathrm{~N}_{4}$ film by $\mathrm{H}_{2}$ or He implantation will be revisited and compared to previously published experimental and simulated works. One key result is that the oxygen coming from chamber contamination is incorporated into $\mathrm{Si}_{3} \mathrm{~N}_{4}$ and that this involuntary contamination plays a key role in the subsequent step. Secondly, in Sec. III B, the etching kinetics of implanted and nonimplanted $\mathrm{Si}_{3} \mathrm{~N}_{4}$ films exposed to $\mathrm{He} / \mathrm{NH}_{3} / \mathrm{NF}_{3}$ remote plasma (RP) will be studied by in situ kinetic ellipsometry. In this section, we will propose new insights into the etching mechanisms of $\mathrm{Si}_{3} \mathrm{~N}_{4}$ films exposed to $\mathrm{NH}_{3} / \mathrm{NF}_{3}$ remote plasma. We will show that RP processes are strongly sensitive to the material surface state and that an incubation time exists before the etching starts. We will especially highlight the key role of the presence of oxygen on the $\mathrm{Si}_{3} \mathrm{~N}_{4}$ surface on the catalysis of the reaction. The introduction of an implantation allows us to functionalize the material surface and thus activate the species adsorption and reaction reducing the incubation time considerably. This offers a process window where the selectivity between implanted and nonimplanted SiN is infinite. Finally, in Sec. III C, we will demonstrate how the cycling of the two steps, implantation followed by RP etching, can be implemented to achieve topographically selective etching, which is one key criteria of the spacer etching process development. 


\section{EXPERIMENTAL}

\section{A. Substrates}

The $\mathrm{Si}_{3} \mathrm{~N}_{4}$ films used in this study are $55 \mathrm{~nm}$-thick and are deposited by low-pressure chemical vapor deposition (LPCVD) at $780^{\circ} \mathrm{C}$ on a $10.5 \mathrm{~nm}$-thick LPCVD silicon oxide itself deposited at $200^{\circ} \mathrm{C}$ on a $300 \mathrm{~mm}$ diameter Si wafer. A silicon on insulator wafer with a $80 \mathrm{~nm}$-thick Si layer (buried oxide layer thickness of $145 \mathrm{~nm}$ ) is also used to investigate the etch kinetics of Si materials exposed to $\mathrm{NH}_{3} / \mathrm{NF}_{3}$ remote plasma in Sec. III C.

\section{B. Plasma reactor}

The experiments are carried out in a $300 \mathrm{~mm}$ prototype etch chamber from Applied Materials (cf. Fig. 1). This chamber is a hybrid plasma processing system incorporating both a remote plasma source (RPS) unit and a capacitively coupled plasma (CCP) unit. The CCP unit (lower chamber) comprises a radio frequency (RF) power supply $(13.56 \mathrm{MHz})$ coupled to the bottom electrode that is equipped with an electrostatic chuck on which the substrate lies. The chuck temperature can be varied from $40^{\circ} \mathrm{C}$ up to $250^{\circ} \mathrm{C}$. The RPS unit (upper chamber) consists of a RF power supply
$(13.56 \mathrm{MHz})$ coupled to the top electrode and is separated from the CCP unit by a lid consisting of several showerheads. The showerheads positioned inside the chamber between the CCP and RPS units act as both a distribution component for gases and an ion suppressor that blocks the ionized species traveling through the showerhead from the plasma region to the substrate. Moreover, the lid temperature is controlled at $130^{\circ} \mathrm{C}$, and the chamber wall is held at $80^{\circ} \mathrm{C}$ by a heat exchanger. The reactor chamber wall is coated with a protective layer of yttrium oxide.

In this study, the CCP unit is used to generate $\mathrm{He}$ or $\mathrm{H}_{2}$ plasmas to implant ions and to induce modifications of the $\mathrm{Si}_{3} \mathrm{~N}_{4}$ films. The plasma conditions used for $\mathrm{He}$ and $\mathrm{H}_{2}$ implantations are given in Table I. Two plasma parameters are critical for the implantation: the ion energy that drives the ion depth penetration and thus the modified layer thickness, and the ion dose (ion flux $\times$ time) that drives the modification rate. ${ }^{14}$ Previous studies done by molecular dynamics simulations have shown that there is an ion dose threshold to reach the steady-state modification. ${ }^{21}$ In this study, we have selected implantation conditions allowing to be in the steady-state regime for both $\mathrm{He}$ and $\mathrm{H}_{2}$ implantations (cf. Table I). Moreover, with the implantation conditions used, the direct current voltage $\mathrm{V}_{\mathrm{dc}}$ is almost similar for $\mathrm{He}$ and $\mathrm{H}_{2}$ implantation, of $120 \mathrm{eV}$ and $130 \mathrm{eV}$, respectively.

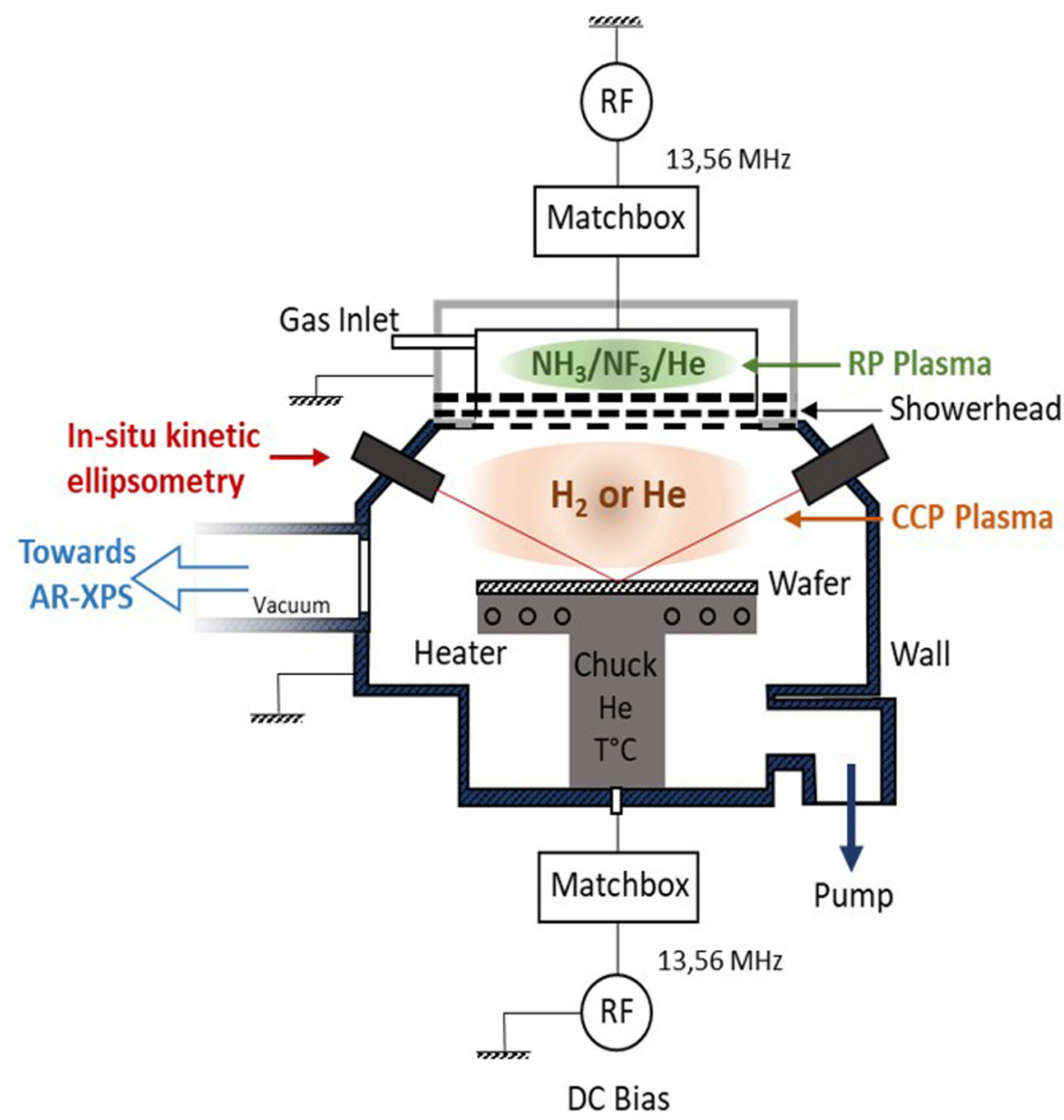

FIG. 1. Scheme of the plasma reactor prototype. 
TABLE I. Plasma conditions used for the $\mathrm{He}$ and $\mathrm{H}_{2}$ implantations on silicon nitride film.

\begin{tabular}{lccccc}
\hline \hline & RF power (W) & $\begin{array}{c}\text { Pressure } \\
(\text { mTorr })\end{array}$ & $\begin{array}{c}\text { Process } \\
\text { time }(\mathrm{s})\end{array}$ & $\begin{array}{c}\text { Gas flow } \\
(\mathrm{sccm})\end{array}$ & $\mathrm{V}_{\mathrm{dc}}(\mathrm{V})$ \\
\hline $\mathrm{H}_{2}$ & 50 & 50 & 60 & 500 & 130 \\
$\mathrm{He}$ & 50 & 50 & 60 & 1000 & 120 \\
\hline \hline
\end{tabular}

The RPS unit is used to perform the chemical and selective removal of the modified $\mathrm{Si}_{3} \mathrm{~N}_{4}$ layers using the following plasma conditions in all the studies: $\mathrm{NH}_{3}: 400 \mathrm{sccm}, \mathrm{NF}_{3}: 40 \mathrm{sccm}$, He: $1400 \mathrm{sccm}$, source power: $250 \mathrm{~W}$, chamber pressure: 2.5 Torr, and Chuck temperature: $60 / 100 / 120^{\circ} \mathrm{C}$.

\section{Characterization techniques}

$\mathrm{X}$-ray reflectometry (XRR), X-ray photoelectron spectroscopy (XPS), and time-of-flight secondary ion mass spectroscopy (ToF-SIMS) were used to characterize the $\mathrm{Si}_{3} \mathrm{~N}_{4}$ films after $\mathrm{He}$ and $\mathrm{H}_{2}$ implantation and provide chemical and physical information on the modified $\mathrm{Si}_{3} \mathrm{~N}_{4}$ layer, while kinetic ellipsometry was used to monitor the etch kinetics of implanted and nonimplanted $\mathrm{Si}_{3} \mathrm{~N}_{4}$ films exposed to RP process.

\section{X-ray reflectometry}

$\mathrm{X}$-ray reflectometry was used to measure the thickness of the $\mathrm{Si}_{3} \mathrm{~N}_{4}$ modified layer after implantation. The XRR equipment (JVX5200T from Jordan Valley) uses a copper source, with a $\mathrm{Cu}-\mathrm{K} \alpha$ emission at $0.154 \mathrm{~nm}$. The convergent beam angle is varied between $0^{\circ}$ and $3.3^{\circ}$ during the experiment. Beside the thickness, this nondestructive method of characterization allows to measure the density and the roughness of the $\mathrm{Si}_{3} \mathrm{~N}_{4}$ films.

\section{Angle-resolved X-ray photoelectron spectroscopy}

The chemical atomic composition of the $\mathrm{Si}_{3} \mathrm{~N}_{4}$ surface (about the first $10 \mathrm{~nm}$ ) before and after implantation is characterized by quasi in situ angle-resolved X-ray photoelectron spectroscopy (ARXPS). A Thermo Electron Theta 300 ARXPS is directly interfaced to the etch platform via a vacuum transfer chamber. The ARXPS system is equipped with a high-resolution monochromatic $\mathrm{Al} \mathrm{Ka} \mathrm{x}$-ray source (1486.6 eV photons). The angle-resolved capability of the Theta 300 is used for all analyses, with eight angles regularly spaced between $23.75^{\circ}$ and $76.25^{\circ}$, referred to the normal of the wafer. A genetic algorithm based on the maximum entropy method (provided by Thermo Fisher Scientific) is used to reconstruct atomic composition depth profiles from angle-resolved XPS data. The fitting procedure assumed that photoelectrons coming from the underlying bulk silicon are detected at a minimum emission angle of $23.75^{\circ}$. This allows maximizing the profile information content. Since the overlayer density is unknown after plasma treatment, the depth scale should be interpreted in a qualitative way (i.e., relative comparison from one experiment to the other and no absolute interpretation of the depth range). ${ }^{22}$

\section{Time-of-flight secondary ion mass spectrometry}

ToF-SIMS experiments using a ToF-SIMS V instrument from ION-TOF GmbH are used to evaluate the chemical composition of the $\mathrm{Si}_{3} \mathrm{~N}_{4}$ films before and after implantation over tens of nanometers in depth. With this technique, the thickness of the $\mathrm{Si}_{3} \mathrm{~N}_{4}$ modified layer after implantation and the in-depth element concentration can be estimated. For the experiments, negative secondary ions are

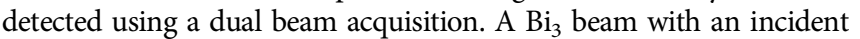
energy of $50 \mathrm{keV}(0.5 \mathrm{nA})$ and a $90 \times 90 \mu \mathrm{m}^{2}$ raster is used for the analysis. This beam is alternated with a positive cesium sputter beam with an energy of $500 \mathrm{eV}$ (for a corresponding current of $40 \mathrm{nA}$ ) that was rastered over a $500 \times 500 \mu \mathrm{m}^{2}$ area. We used a cycle time of $140 \mu \mathrm{s}$ with a corresponding cycle of acquisition of 4 frames and $1 \mathrm{~s}$ sputtering with $1 \mathrm{~s}$ pause time between two acquisitions.

\section{Kinetic ellipsometry}

Kinetic ellipsometry is used to monitor in real time the etched thickness of the materials exposed to the RPS process. A multiwavelength ellipsometer Uvisel from Horiba/Jobin Yvon is directly connected to the prototype reactor allowing in situ measurement of the material thickness. This phase-modulated ellipsometer enables in situ spectroscopic ellipsometry between 1.5 and $6.2 \mathrm{eV}$ and realtime kinetic measurements using 32 wavelengths with a time resolution of $500 \mathrm{~ms}$. The light source consists of a $75 \mathrm{~W}$ Xe lamp, and the light beam incident angle is of $62^{\circ}$ to the normal of the wafer surface. The polarizer and analyzer are glan type devices with an extinction coefficient of $10^{-5}$ and an angular precision of $0.01^{\circ}$ at a fixed angle. The thickness of the materials was calculated using the DeltaPsi II software, developed by Horiba/Jobin Yvon. It has already been reported that the etching of $\mathrm{Si}_{3} \mathrm{~N}_{4}$ or $\mathrm{SiO}_{2}$ films exposed to $\mathrm{NH}_{3} / \mathrm{NF}_{3}$ remote plasma proceeds with the formation of an ammonium hexafluorosilicate $\left(\mathrm{NH}_{4}\right)_{2} \mathrm{SiF}_{6}$ salt layer on their surface. ${ }^{17,23-25}$ Figures 2(a) and 2(b) show the scanning electronic microscopy (SEM) and atomic force microscopy (AFM) images of the salt layer formed on a $\mathrm{Si}_{3} \mathrm{~N}_{4}$ film exposed to the $\mathrm{NH}_{3} / \mathrm{NF}_{3} \mathrm{RP}$ process at $60^{\circ} \mathrm{C}$. It looks like a tangle of polycrystals separated with cracks and voids. Based on these observations, an ellipsometric model is developed to fit the bilayer composed of the unmodified $\mathrm{Si}_{3} \mathrm{~N}_{4}$ film above which a salt layer is formed [cf. Fig. 2(c)].

The dispersion model of the silicon nitride film uses a new amorphous dispersion relationship that is derived on the basis of the Forouhi-Bloomer formulation with tabulated optical constants. ${ }^{26}$ The refractive index is about 2 at $632.8 \mathrm{~nm}$, which is in agreement with the literature for thin LPCVD nitride films. ${ }^{27}$ The salt layer is fitted with the Cauchy absorbent dispersion law coupled with a void simulation (Cauchy Transparent) to take into account the porosity of the salt layer. The fitting procedure results in the following salt dispersion law that is fixed for all the experiments:

$$
\text { Salt model: }\left\{n(\lambda)=A+\frac{B \times 10^{4}}{\lambda^{2}}+\frac{C \times 10^{9}}{\lambda^{4}} ; k(\lambda)=D \times 10^{-5}+\frac{E \times 10^{4}}{\lambda^{2}}+\frac{F \times 10^{9}}{\lambda^{4}}\right\}+\text { void. }
$$



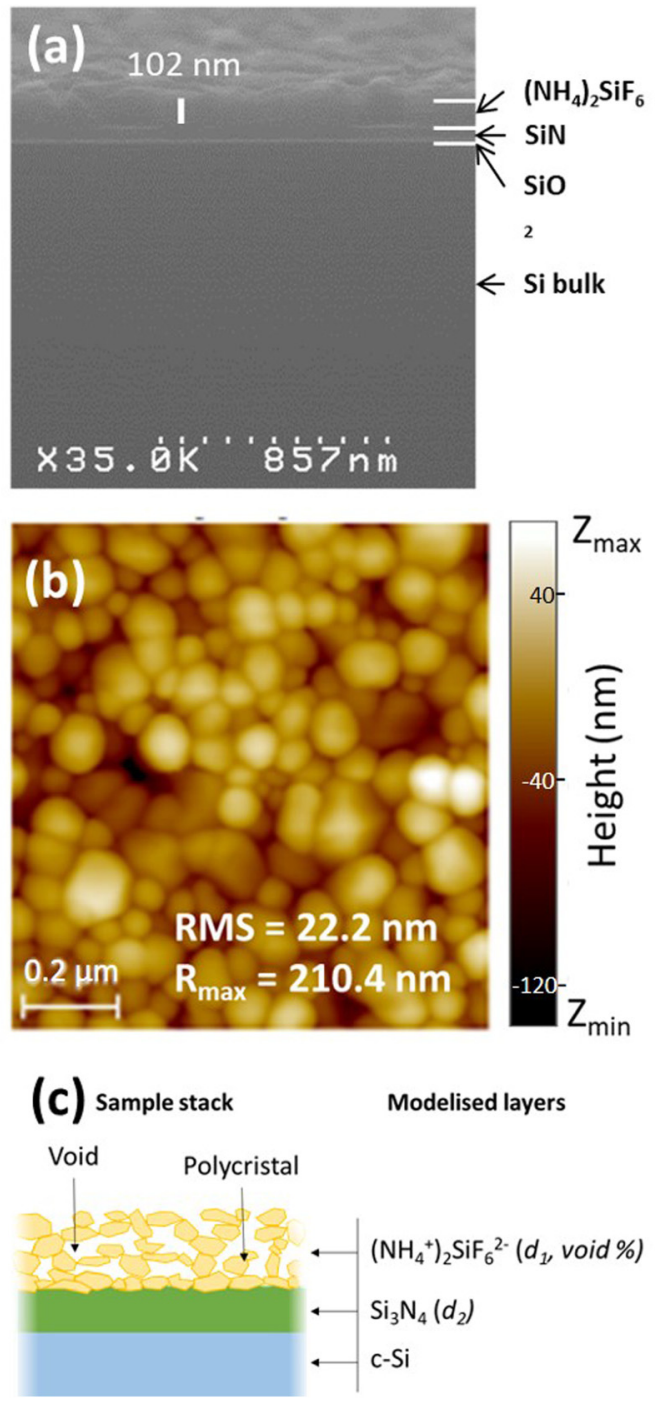

FIG. 2. (a) SEM image and (b) AFM image of the ammonium salt layer formed on $\mathrm{Si}_{3} \mathrm{~N}_{4}$ film exposed to $\mathrm{NH}_{3} / \mathrm{NF}_{3} / \mathrm{He}$ remote plasma at $60^{\circ} \mathrm{C}$. (c) Schematic of the bilayer model used to fit the ellipsometric data of $\mathrm{Si}_{3} \mathrm{~N}_{4}$ films exposed to $\mathrm{NH}_{3} / \mathrm{NF}_{3} \mathrm{RP}$ process. Free fitting parameters are the thicknesses of the salt $\left(d_{1}\right)$ and $\mathrm{Si}_{3} \mathrm{~N}_{4}\left(\mathrm{~d}_{2}\right)$ layers, as well as the salt porosity (void \%).

After the fitting procedure, the following values were found for the coefficients of the salt dispersion law: $A=3.53 ; B=E=0$; $C=0.47 ; D=10$; and $F=0.17$.

This model was used to describe the etching kinetics of $\mathrm{Si}_{3} \mathrm{~N}_{4}$ films exposed to the $\mathrm{NH}_{3} / \mathrm{NF}_{3}$ RPS process conditions used in this study (wafer temperature of $100{ }^{\circ} \mathrm{C}$ and a chamber pressure of 2.5 Torr). Indeed, in these conditions, the salt layer is formed during the $\mathrm{Si}_{3} \mathrm{~N}_{4}$ etching, but it outgasses in the chamber at the end of the process during the pump down to reach base pressure $\left(<1 \mathrm{mTorr}\right.$ ) (which is not the case at $60^{\circ} \mathrm{C}$ ), preventing from ex situ analyses (cf. Sec. III B 2). This is why the ellipsometric model was developed for the RP process operating at $60^{\circ} \mathrm{C}$ but was then implemented for the monitoring of $\mathrm{Si}_{3} \mathrm{~N}_{4}$ etching in $\mathrm{NH}_{3} / \mathrm{NF}_{3} \mathrm{RP}$ at $100{ }^{\circ} \mathrm{C}$. For the fitting of the kinetic data, the dispersion laws of the unmodified $\mathrm{Si}_{3} \mathrm{~N}_{4}$ and the salt layers are fixed. Only the layer thicknesses and the salt porosity can be varied.

However, we noticed that the porosity was almost constant during the process and comprised between $77 \%$ and $82 \%$.

\section{RESULTS AND DISCUSSION}

\section{A. Characterization of $\mathrm{Si}_{3} \mathbf{N}_{4}$ films after implantation}

In Sec. III $A$, the $\mathrm{Si}_{3} \mathrm{~N}_{4}$ wafers are exposed to $\mathrm{H}_{2}$ or $\mathrm{He}$ implantations using the plasma conditions given in Table I.

XRR is first used to determine the thickness of the modified $\mathrm{Si}_{3} \mathrm{~N}_{4}$ by implantation.

The XRR measurement of a pristine $\mathrm{Si}_{3} \mathrm{~N}_{4}$ film before implantation is fitted with a bilayer [cf. Fig. 3(a): a $1.1 \mathrm{~nm}$-thick native $\mathrm{Si}_{3} \mathrm{~N}_{4}$ oxide layer with a density of $2.5 \mathrm{~g} \mathrm{~cm}^{-3}$ over a $53.2 \mathrm{~nm}$-thick $\mathrm{Si}_{3} \mathrm{~N}_{4}$ with a density of $3.0 \mathrm{~g} / \mathrm{cm}^{3}$ ]. After implantation, our first approach was to fit the XRR data with a bilayer: a first top layer corresponding to the $\mathrm{Si}_{3} \mathrm{~N}_{4}$ layer modified by the implantation over an unmodified $\mathrm{Si}_{3} \mathrm{~N}_{4}$ layer [cf. Fig. 3(b)]. In the case of $\mathrm{H}_{2}$ implantation, the fitting procedure indicates that a $5.8 \mathrm{~nm}$-thick modified layer with a density of $2.3 \mathrm{~g} \mathrm{~cm}^{-3}$ lower than the pristine $\mathrm{Si}_{3} \mathrm{~N}_{4}$ is formed at the surface of the unmodified $\mathrm{Si}_{3} \mathrm{~N}_{4}$ layer. However, with this bilayer model, the fit curve derives from the experimental data points for high angles of incidence $\left(\theta>1.8^{\circ}\right)$. Figure $3(\mathrm{c})$ shows that a fitting procedure using a trilayer model offers a better match with the experimental data with a decrease of the sum of squared error from 0.231 to 0.168 . The trilayer model leads globally to the same conclusion as the bilayer one: the $\mathrm{H}_{2}$ implantation using the plasma conditions of Table I results in a total modified $5.8 \mathrm{~mm}$ thick $\mathrm{Si}_{3} \mathrm{~N}_{4}$ layer having a lower density than the pristine $\mathrm{Si}_{3} \mathrm{~N}_{4}$ and does not introduce significant sputtering or swelling (since the total $\mathrm{Si}_{3} \mathrm{~N}_{4}$ thickness before and after implantation for both models is around $54.0 \pm 0.5 \mathrm{~nm}$ ). However, the trilayer model suggests that a thin layer (of about $1 \mathrm{~nm}$ thick) with an even lower density $\left(2 \mathrm{~g} \mathrm{~cm}^{-3}\right)$ is formed at the very top surface $(<1 \mathrm{~nm})$. This cannot be attributed to surface roughness generation during implantation since AFM measurements performed before and after implantation show almost similar RMS roughness of $0.26 \mathrm{~nm}$ and $0.43 \mathrm{~nm}$, respectively (not shown here). Similar findings are made with $\mathrm{He}$ implantation. The fitting procedure using the trilayer model shown in Fig. 3(d) indicates that $\mathrm{He}$ implantation using the plasma conditions of Table I results in a total modified $4 \mathrm{~mm}$ thick $\mathrm{Si}_{3} \mathrm{~N}_{4}$ layer composed of a thin and low density top modified layer $\left(0.8 \mathrm{~nm} / 1.2 \mathrm{~g} \mathrm{~cm}^{-3}\right)$ and an underneath intermediate modified layer $\left(3.2 \mathrm{~nm} / 2.6 \mathrm{~g} \mathrm{~cm}^{-3}\right)$. No sputtering or swelling is also measured.

It is noticed that for similar ion energy, the implanted depth is higher for $\mathrm{H}_{2}$ than $\mathrm{He}$ implantation since smaller $\mathrm{H}^{+}$ions penetrate deeper into materials. ${ }^{14}$ Moreover, the density decrease induced by the implantation is much important after $\mathrm{H}_{2}(25 \%)$ than $\mathrm{He}(12 \%)$ implantation. This density decrease had already been predicted by molecular dynamics simulations performed by Martirosyan et al. ${ }^{21}$ In their study, they estimated a density decrease of $7 \%$ of the modified $\mathrm{Si}_{3} \mathrm{~N}_{4}$ by $\mathrm{He}$ implantation using $50 \mathrm{eV}$ ion energy. 
(a)

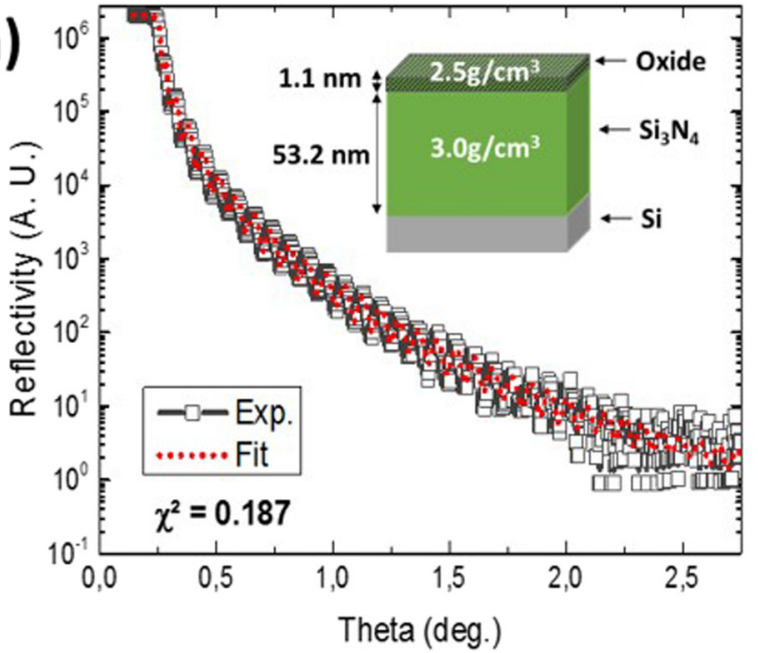

(c)

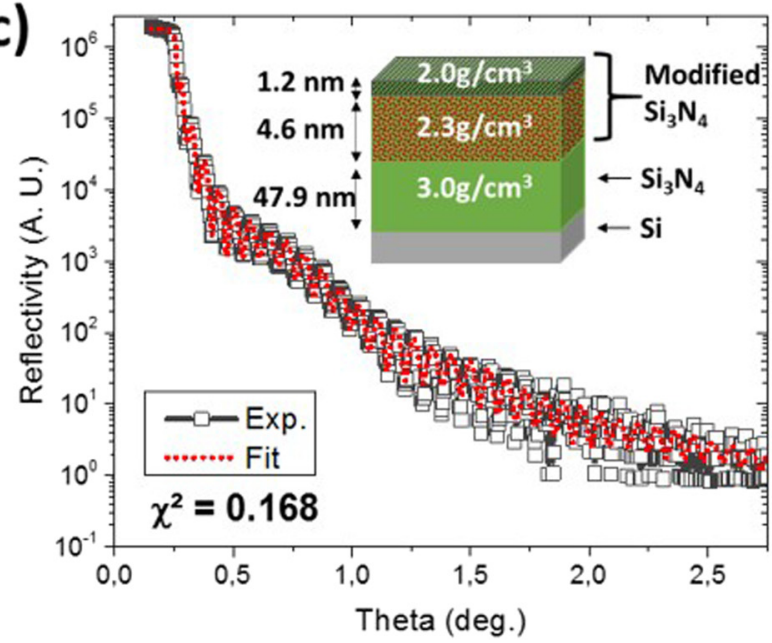

(b)

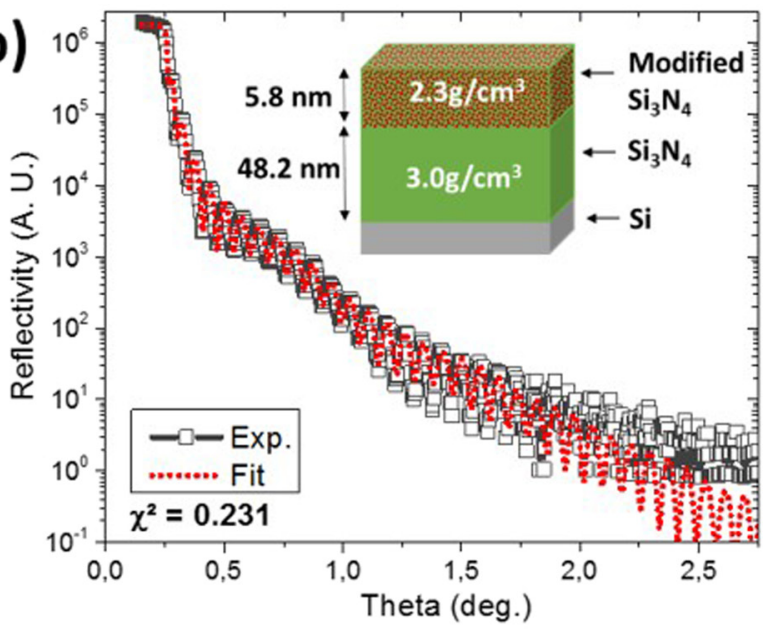

(d)

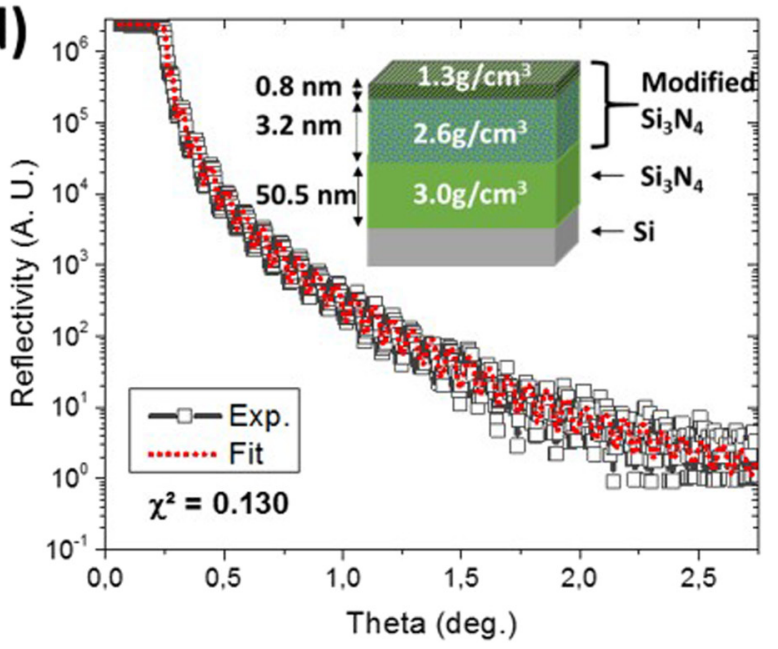

FIG. 3. XRR experimental data (black open squares) and fitting curve (dot red line) of (a) pristine $\mathrm{Si}_{3} \mathrm{~N}_{4}$ film, (b) $\mathrm{Si}_{3} \mathrm{~N}_{4}$ film after $\mathrm{H}_{2}$ implantation using a bilayer model for the fit, (c) $\mathrm{Si}_{3} \mathrm{~N}_{4}$ film after $\mathrm{H}_{2}$ implantation using a trilayer model for the fit, and (d) $\mathrm{Si}_{3} \mathrm{~N}_{4}$ film after He implantation using a trilayer model for the fit.

To consolidate these results, the total modified thicknesses were compared to the profiles given by the Monte Carlo code Stopping and Range of Ions in Matters (SRIM) developed by Ziegler. ${ }^{28}$ For our simulations, the substrate had a thickness of $54 \mathrm{~nm}$ and a density of $3.0 \mathrm{~g} \mathrm{~cm}^{-3}$ in accordance with the XRR characterization of the pristine LPCVD silicon nitride film. We estimated the simulated thickness of the implanted layer by summing the mean projected range $\left(R_{p}\right)$ and the square root of the variance. The penetration depth calculated with SRIM simulation are $5.6 \mathrm{~nm}$ and $3.3 \mathrm{~nm}$ for hydrogen and helium, respectively. These values are very close to the experimental modified thickness determined by XRR $\left(5.8 \mathrm{~nm}\right.$ after $\mathrm{H}_{2}$ implantation and $4 \mathrm{~nm}$ after He implantation) confirming that the modified thickness corresponds indeed to the depth at which $\mathrm{H}^{+}$or $\mathrm{He}$ ions can penetrate into the $\mathrm{Si}_{3} \mathrm{~N}_{4}$ material with the used ion energy.

Quasi in situ ARXPS analyses have also been carried out after $\mathrm{He}$ and $\mathrm{H}_{2}$ implantations. Prior to the implantation, the $\mathrm{Si}_{3} \mathrm{~N}_{4}$ films are deoxidized with an HF bath. Three chemical elements are detected: $\mathrm{Si}, \mathrm{N}$, and $\mathrm{O}$. He and $\mathrm{H}$ cannot be detected by XPS if present. Thanks to the angular resolution of our spectrometer, the depth profiles of oxygen atomic concentration for HF-deoxidized $\mathrm{Si}_{3} \mathrm{~N}_{4}$ films before and after $\mathrm{He}$ or $\mathrm{H}_{2}$ implantation can be reconstructed as shown in Fig. 4. The depth profiles for pristine $\mathrm{Si}_{3} \mathrm{~N}_{4}$ with its native oxide are also represented for comparison. Figure 4 confirms the efficiency of $\mathrm{HF}$ wet etchant to deoxidize the $\mathrm{Si}_{3} \mathrm{~N}_{4}$ (even though some $\mathrm{O}$ traces remain). After implantation, the amount of $\mathrm{O}$ at the very near surface is clearly increased and is detected within the first nanometer of the surface. As XPS analyses are achieved in a quasi in situ way, it is likely that this oxygen comes from the $\mathrm{Y}_{2} \mathrm{O}_{3}$ reactor wall or residual oxygen in the chamber. The oxidation of InGaAs after He implantation has also been observed in relatively similar conditions by Bizouerne and co-workers. ${ }^{29}$ They explained that if contaminants are present in 


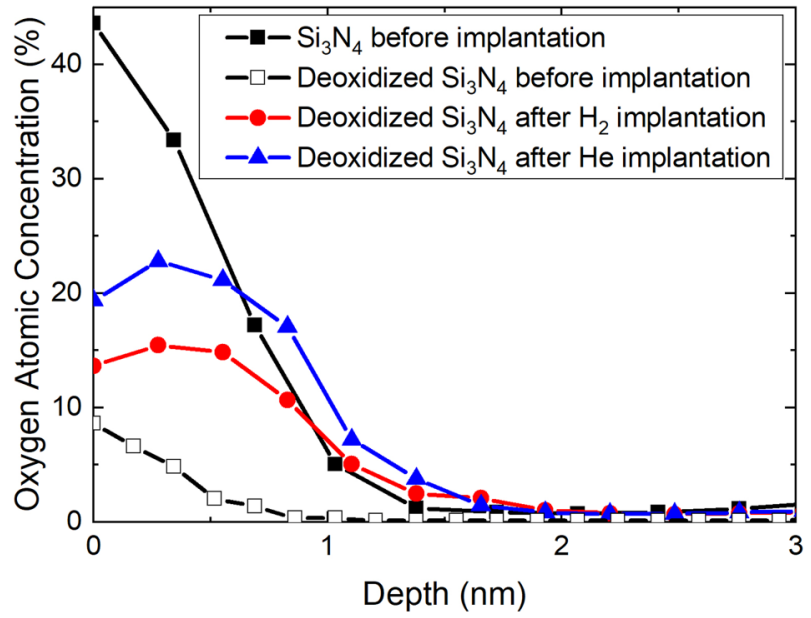

FIG. 4. ARXPS depth profile of the oxygen atomic concentration of HF-deoxidized $\mathrm{Si}_{3} \mathrm{~N}_{4}$ films before (black empty square) and after hydrogen (red circle) and helium (blue triangle) implantations compared to the one of pristine $\mathrm{Si}_{3} \mathrm{~N}_{4}$ with its native oxide (full black square).

the $\mathrm{He}$ gas phase, they will be more likely ionized compared to helium because their ionization potential is much lower than the one of helium (He: $24.59 \mathrm{eV}$ and $\mathrm{O}: 13.62 \mathrm{eV}$ ) and will also be implanted. ${ }^{30}$ The amount of oxygen is higher after $\mathrm{He}$ than $\mathrm{H}_{2}$ implantation, but we noticed that the amount of implanted $\mathrm{O}$ is very dependent on the reactor wall conditioning and no conclusion can be drawn on which between $\mathrm{He}$ or $\mathrm{H}$ implantation brings more contaminants. We suspect that this thin layer rich in O contaminants corresponds to the top surface layer detected by XRR.

Besides highlighting the presence of oxygen at the $\mathrm{Si}_{3} \mathrm{~N}_{4}$ surface, ARXPS analyses also allowed us to estimate the stoichiometry of the silicon nitride film after the implantation. Figure 5 shows the $\mathrm{N} / \mathrm{Si}$ atomic ratio as a function of the probed depth for implanted and nonimplanted $\mathrm{Si}_{3} \mathrm{~N}_{4}$ films. For the pristine $\mathrm{Si}_{3} \mathrm{~N}_{4}$ sample, the N/Si ratio is almost constant on the probed depth and is equal to 1.5 , which is slightly higher than the expected theoretical ratio of 1.33 for stoichiometric $\mathrm{Si}_{3} \mathrm{~N}_{4}$. After both $\mathrm{He}$ and $\mathrm{H}_{2}$ implantations, a nitrogen depletion is observed at the very top surface (within the first nanometer) and a nitrogen enrichment below at 1-3 nm depth. Finally, the $\mathrm{Si}_{3} \mathrm{~N}_{4}$ film tends to recover its initial stoichiometry at about $3 \mathrm{~nm}$ of depth. This trend is fully consistent with the prediction of the molecular dynamics simulations by Martirosyan et al. ${ }^{21}$ They predict that the He ion implantation into $\mathrm{Si}_{3} \mathrm{~N}_{4}$ films leads to a rearrangement of the bonds. The $\mathrm{Si}-\mathrm{N}$ bonds are broken in all the modified volume and are accompanied by the formation of $\mathrm{Si}-\mathrm{Si}$ bonds within the first nanometer and the formation of N-N bonds just below. The nitrogen depletion of the near surface is mostly attributed to the preferential sputtering of nitrogen atoms compared to that of silicon atoms due to the more efficient collisional energy transfer between $\mathrm{N}-\mathrm{He}$ compared to $\mathrm{Si}-\mathrm{He}$. In our case, we do not see the formation of $\mathrm{Si}-\mathrm{Si}$ bonds at the very near surface, but instead see $\mathrm{Si}-\mathrm{O}$ bonds. Indeed, molecular dynamics simulations do not take into account the presence of

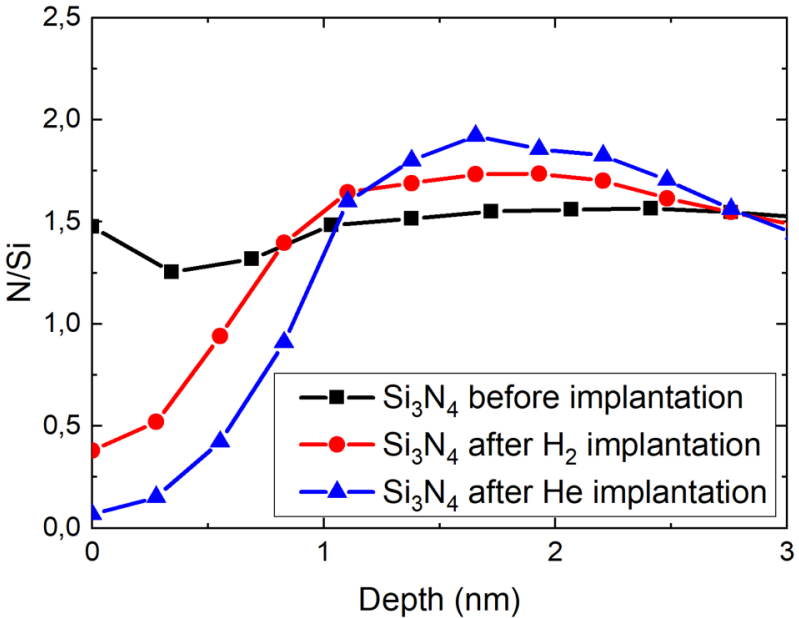

FIG. 5. N/Si atomic ratio as a function of the depth probed by ARXPS of deoxidized $\mathrm{Si}_{3} \mathrm{~N}_{4}$ film before (black square) and after $\mathrm{H}_{2}$ (red circle) and $\mathrm{He}$ (blue triangle) implantations.

oxygen contaminants during the implantation. It is likely that $\mathrm{Si}-\mathrm{O}$ bonds are more likely formed than $\mathrm{Si}-\mathrm{Si}$ bonds following the cleavage of the $\mathrm{Si}_{3} \mathrm{~N}_{4}$ bond during the He implantation.

Ex situ ToF-SIMS analyses were carried out after $\mathrm{He}$ and $\mathrm{H}_{2}$ implantations. Unfortunately, $\mathrm{He}$ could not be detected by ToF-SIMS because no detectable secondary ions could be formed due to its high ionization energy. The ToF-SIMS experiments obtained after He implantation do not bring any complementary information and are thus not shown here. The hydrogen and oxygen in-depth distributions obtained on $\mathrm{H}_{2}$ implanted $\mathrm{Si}_{3} \mathrm{~N}_{4}$ films by ToF-SIMS are represented in Fig. 6.

The simplest formula for expressing an implantation profile is a Gaussian distribution. However, real ion implantation profiles are often asymmetric and the symmetric Gaussian function cannot model the tail of the distribution. Several models have been proposed to take into account this tail and get an accurate implantation profile reconstruction including the addition of an exponential tail function ${ }^{31}$ or the use of a joined half-Gaussian. ${ }^{32}$

In our case, the presence of a positive skew could be attributed to the bimodal distribution of ion energy in the CCP discharge that leads to the fit of two half-Gaussians. ${ }^{33}$

The ToF-SIMS profiles of Fig. 6 have been fitted using a probability distribution based on two half-Gaussian distributions as proposed by Gibbons et al. [cf. Eq. (1)], ${ }^{32}$

$$
n(x)= \begin{cases}\sqrt{\frac{2}{\pi}} \frac{\Phi}{\left(\sigma_{p f}+\sigma_{p b}\right)} \exp \left[-\frac{\left(x-R_{p m}\right)^{2}}{2 \sigma_{p f}^{2}}\right] & \text { for } x \leq R_{p m}, \\ \sqrt{\frac{2}{\pi}} \frac{\Phi}{\left(\sigma_{p f}+\sigma_{p b}\right)} \exp \left[-\frac{\left(x-R_{p m}\right)^{2}}{2 \sigma_{p b}^{2}}\right] & \text { for } x>R_{p m},\end{cases}
$$

where $n(x)$ represents the concentration, $\Phi$ is the ion dose per unit, $R_{p m}$ is the projected range, $\sigma_{p f}$ is the standard deviation of the 


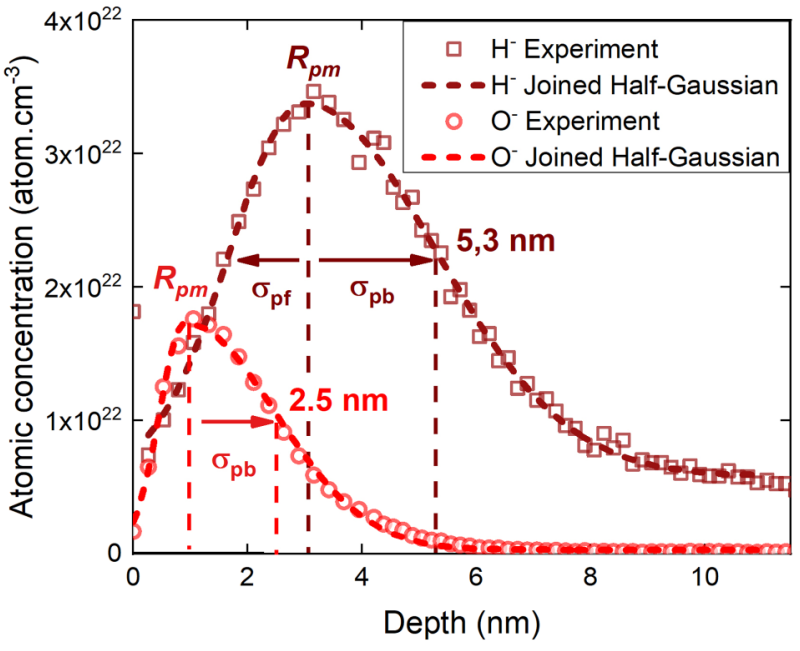

FIG. 6. In-depth $\mathrm{H}^{-}$(empty purple square) and $\mathrm{O}^{-}$(empty red circle) distribution in a $\mathrm{Si}_{3} \mathrm{~N}_{4}$ film after $\mathrm{H}_{2}$ implantation (ToF-SIMS, $\mathrm{Cs}^{+} / 500 \mathrm{eV}$ ) fitted with a two half-Gaussian model.

Gaussian profile between $R_{p m}$ and the surface, and $\sigma_{p f}$ is the standard deviation of the Gaussian profile below $R_{p m}$. The values found for the parameters $\Phi, R_{p m}, \sigma_{p f}$, and $\sigma_{p b}$ for the $\mathrm{O}$ and $\mathrm{H}$ depth profiles are represented in Table II.

The agreement between the experimental and fitting data confirms that the ToF-SIMS $\mathrm{O}$ and $\mathrm{H}$ profiles correspond to those of the implanted species. The penetration depth is estimated to be of $R_{p m}+\sigma_{p b}$, namely, $2.5 \mathrm{~nm}$ and $5.3 \mathrm{~nm}$ for $\mathrm{O}$ and $\mathrm{H}$, respectively.

The $\mathrm{O}$ penetration depth estimated by ToF-SIMS is more important than the thickness of the top modified surface layer detected by XRR [only of $1.1 \mathrm{~nm}$, cf. Fig. 3(c)]. We assume that the XRR technique is not robust enough to discriminate the thickness of the two layers presenting gradients in the concentration and having close densities. On the contrary, the depth at which $\mathrm{H}$ penetrates into the $\mathrm{Si}_{3} \mathrm{~N}_{4}$ film deducted from the model is quite consistent with the total modified layer estimated by XRR [of $5.8 \mathrm{~nm}$, cf. Fig. 3(c)]. Experimentally, using infrared characterizations, Posseme et al. ${ }^{17}$ found that the implanted $\mathrm{H}$ forms $\mathrm{NH}$ and $\mathrm{SiH}$ bonds. More precisely, the dynamic molecular simulation of Martirosyan ${ }^{34}$ of $\mathrm{H}_{2}$ implantation of $\mathrm{Si}_{3} \mathrm{~N}_{4}$ films reveal that $\mathrm{SiH}_{3}$ bonds are mainly formed at the $\mathrm{H}$ peak maximum concentration, while $\mathrm{SiH}_{2}$ dominates in the rest of the modified layer followed by $\mathrm{SiH}$ and then $\mathrm{NH}$.

To summarize this part, we have seen that $\mathrm{He}$ or $\mathrm{H}_{2}$ implantation can chemically modify the first nanometers of the $\mathrm{Si}_{3} \mathrm{~N}_{4}$

TABLE II. Values of the parameters of the two half-Gaussian equations used to fit the $\mathrm{O}^{-}$and $\mathrm{H}^{-}$profiles [cf. Eq. (1)].

\begin{tabular}{ccccc}
\hline \hline & $R_{p m}(\mathrm{~nm})$ & $\sigma_{p f}(\mathrm{~nm})$ & $\sigma_{p b}(\mathrm{~nm})$ & $\Phi\left(\right.$ at nm $\left.^{-1}\right)$ \\
\hline $\mathrm{O}^{-}$ & 0.9 & 0.4 & 1.6 & $2.7 \times 10^{27}$ \\
$\mathrm{H}^{-}$ & 3.0 & 1.3 & 2.3 & $8 \times 10^{22}$ \\
\hline \hline
\end{tabular}

surface. With ion energies of $120 \mathrm{eV}$ and $130 \mathrm{eV}$ being used for $\mathrm{He}$ and $\mathrm{H}_{2}$ implantation, respectively, $\mathrm{Si}_{3} \mathrm{~N}_{4}$ is modified on the first 4.0 and $5.8 \mathrm{~nm}$, respectively, consistently with SRIM simulations. In both cases, the modified layer consists of a bilayer: a near surface layer of about $1-2 \mathrm{~nm}$ thick with a low density (of $2 \mathrm{~g} \mathrm{~cm}^{-3}$ and $1.3 \mathrm{~g} \mathrm{~cm}^{-3}$ for hydrogen and helium implantation, respectively), depleted in nitrogen and rich in oxygen contaminants, and a disorganized sublayer with lower density than the pristine $\mathrm{Si}_{3} \mathrm{~N}_{4}$ (about $2.3-2.6 \mathrm{~g} \mathrm{~cm}^{-3}$ ) and slightly richer in nitrogen than the pristine materials (certainly via the formation of $\mathrm{N}-\mathrm{N}$ bonds). In the case of $\mathrm{H}_{2}$ implantation, it is possible to detect the presence of $\mathrm{H}$ in the $\mathrm{Si}_{3} \mathrm{~N}_{4}$ material after implantation over the entire depth of the modified layer thickness using the ToF-SIMS analyses.

From molecular dynamics simulations, ${ }^{21}$ it is also suspected that $\mathrm{He}$ is present in the modified layer of the He-implanted $\mathrm{Si}_{3} \mathrm{~N}_{4}$, although we could not prove it experimentally. Finally, we systematically observe the implantation of oxygen contaminants at the very near $\mathrm{Si}_{3} \mathrm{~N}_{4}$ surface after both $\mathrm{He}$ and $\mathrm{H}_{2}$, which could not be predicted by the molecular dynamics simulation and may play a role in the RP etching mechanisms as described in Sec. III B.

\section{B. Etching kinetics of $\mathrm{Si}_{3} \mathrm{~N}_{4}$ films in $\mathrm{NH}_{3} / \mathrm{NF}_{3} / \mathrm{He}$ remote plasma}

In Sec. III B, pristine and implanted $\mathrm{Si}_{3} \mathrm{~N}_{4}$ wafers are exposed

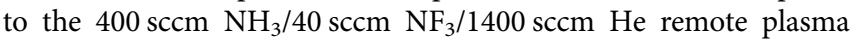
using $250 \mathrm{~W}$ as the source power and 2.5 Torr as the pressure chamber

\section{Pristine $\mathrm{Si}_{3} \mathrm{~N}_{4}$}

The etching kinetics of pristine $\mathrm{Si}_{3} \mathrm{~N}_{4}$ films exposed to $\mathrm{NH}_{3} /$ $\mathrm{NF}_{3} / \mathrm{He}$ remote plasma at $100^{\circ} \mathrm{C}$ have been investigated by realtime ellipsometry. As already mentioned, the etching proceeds with the formation of an ammonium salt layer on the surface. The plasma reactive species absorb on the surface, react with $\mathrm{Si}_{3} \mathrm{~N}_{4}$, and turn $\mathrm{Si}_{3} \mathrm{~N}_{4}$ into a salt. Similar to silicon oxidation mechanisms, the salt formation leads to $\mathrm{Si}_{3} \mathrm{~N}_{4}$ consumption. For each processing time, the kinetic data are fitted with a bilayer composed of a salt layer over an unmodified $\mathrm{Si}_{3} \mathrm{~N}_{4}$ layer, with the dispersion law described in Sec. II C 4.

Figure 7(a) compares the consumed thickness of the pristine $\mathrm{Si}_{3} \mathrm{~N}_{4}$ film with its native oxide and the $\mathrm{Si}_{3} \mathrm{~N}_{4}$ film deoxidized with a $1 \% \mathrm{HF}$ wet etchant when exposed to the $\mathrm{NH}_{3} / \mathrm{NF}_{3} / \mathrm{He} \mathrm{RP}$. For the deoxidized sample, no salt formation is detected even after a very long processing time of $1000 \mathrm{~s}$, as well as no $\mathrm{Si}_{3} \mathrm{~N}_{4}$ consumption. For the pristine $\mathrm{Si}_{3} \mathrm{~N}_{4}$, an etch delay of about $70 \mathrm{~s}$ is observed before the etching starts. We assume that this delay corresponds to the time needed for the reactive neutrals of the remote plasma to adsorb on the surface and then react with the substrate. This preliminary observation tends to suggest that the surface oxidation state plays a key role in the etching mechanisms and that oxygen acts as a reaction catalyst. After this incubation time, a salt layer starts to grow causing the $\mathrm{Si}_{3} \mathrm{~N}_{4}$ consumption. Figure 7(b) shows that there is a linear relation between the salt layer thickness and the consumed $\mathrm{Si}_{3} \mathrm{~N}_{4}$ thickness, with a correlation coefficient of 6.1. Other experiments not shown here indicate that this coefficient depends on the nature of the etched material but also on the 

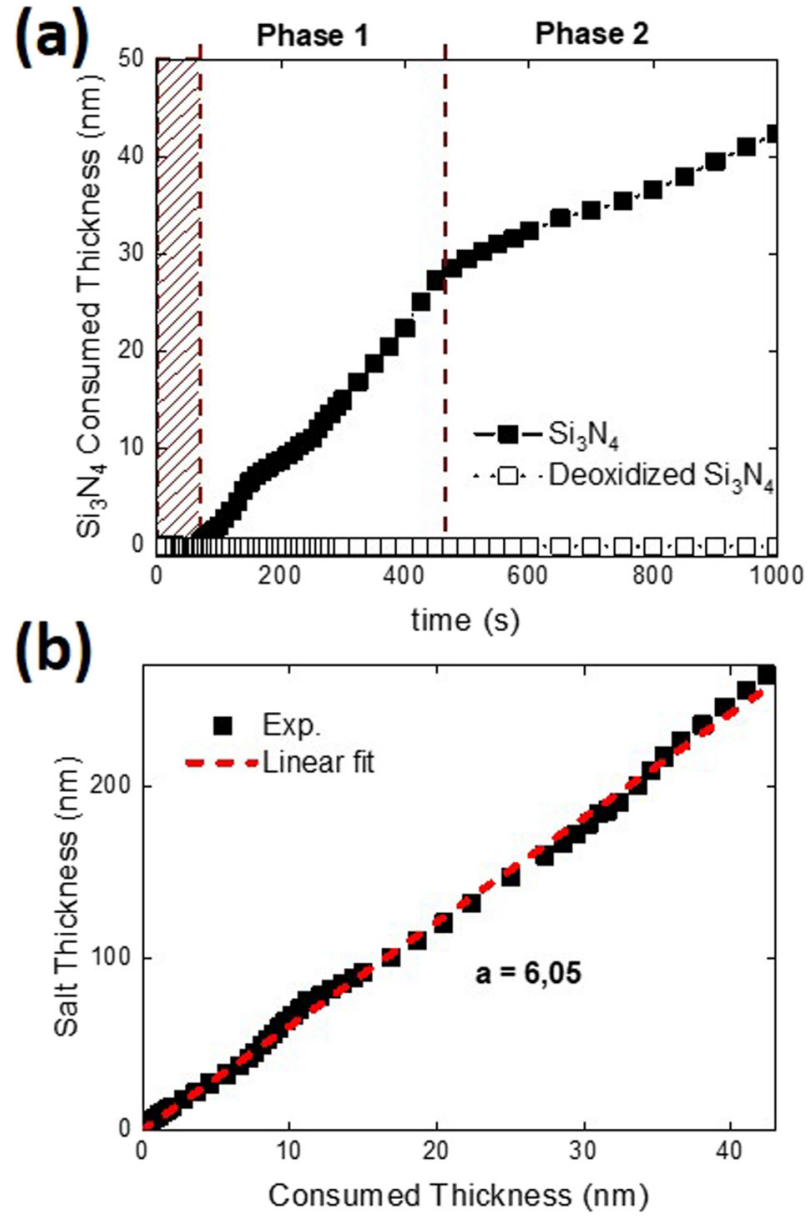

FIG. 7. (a) Etching kinetics of HF-deoxidized (empty black square) and pristine (full black square) $\mathrm{Si}_{3} \mathrm{~N}_{4}$ in $\mathrm{NH}_{3} / \mathrm{NF}_{3} / \mathrm{He}$ remote plasma at $100{ }^{\circ} \mathrm{C}$. (b) Salt thickness as a function of the consumed $\mathrm{Si}_{3} \mathrm{~N}_{4}$ thickness.

substrate temperature and the $\mathrm{NH}_{3} / \mathrm{NF}_{3}$ ratio introduced in the remote plasma gas phase (this will be discussed in another publication). This reaction mechanism implies that the $\mathrm{Si}_{3} \mathrm{~N}_{4}$ layer is constantly consumed with a growing salt layer upon its surface.

As shown in Fig. $7(\mathrm{a})$, the $\mathrm{Si}_{3} \mathrm{~N}_{4}$ consumption is not linear with time and slows down with a longer exposure time (here above $475 \mathrm{~s})$. This indicates that above a certain salt thickness on the $\mathrm{Si}_{3} \mathrm{~N}_{4}$ film (here of $166.7 \mathrm{~nm}$ corresponding to $28.6 \mathrm{~nm}$ of etched $\mathrm{Si}_{3} \mathrm{~N}_{4}$ after $475 \mathrm{~s}$ of $\mathrm{RP}$ ), the $\mathrm{Si}_{3} \mathrm{~N}_{4}$ consumption is limited by the reactive neutral diffusion through the salt layer until the salt/ $\mathrm{Si}_{3} \mathrm{~N}_{4}$ interface. It is also interesting to highlight that the etching of the pristine $\mathrm{Si}_{3} \mathrm{~N}_{4}$ is not limited to the depth at which it is oxidized (about $2 \mathrm{~nm}$ ), meaning that once the salts are formed, fluorine and hydrogen present in the salt can diffuse through the interface and consume $\mathrm{Si}_{3} \mathrm{~N}_{4}$ while the plasma still supplies the salt layer with reactive species. Once the RP is turned off (at the end of the experiment), the pressure in the chamber is decreased down to the chamber base pressure $(<1 \mathrm{mTorr})$, while the wafer is still at the process temperature of $100{ }^{\circ} \mathrm{C}$. During this step, the ammonium salts are outgassed leaving a clean surface without any fluorinated ammonium residues. To illustrate and demonstrate this point, two experiments have been performed (cf. Fig. 8). The first experiment consists of exposing the pristine $\mathrm{Si}_{3} \mathrm{~N}_{4}$ to the $\mathrm{NH}_{3} / \mathrm{NF}_{3} / \mathrm{He} \mathrm{RP}$ process at 2.5 Torr for $150 \mathrm{~s}$ (stage 1); then, the plasma is turned off and the gas is evacuated to decrease the pressure down to the chamber base pressure while the wafer is still maintained at $100{ }^{\circ} \mathrm{C}$ (stage 2,170 s); finally, the RP process at 2.5 Torr is turned on again during $150 \mathrm{~s}$ (stage 3 ). The second experiment is similar except for the second stage. Instead of evacuating the reactive gas,
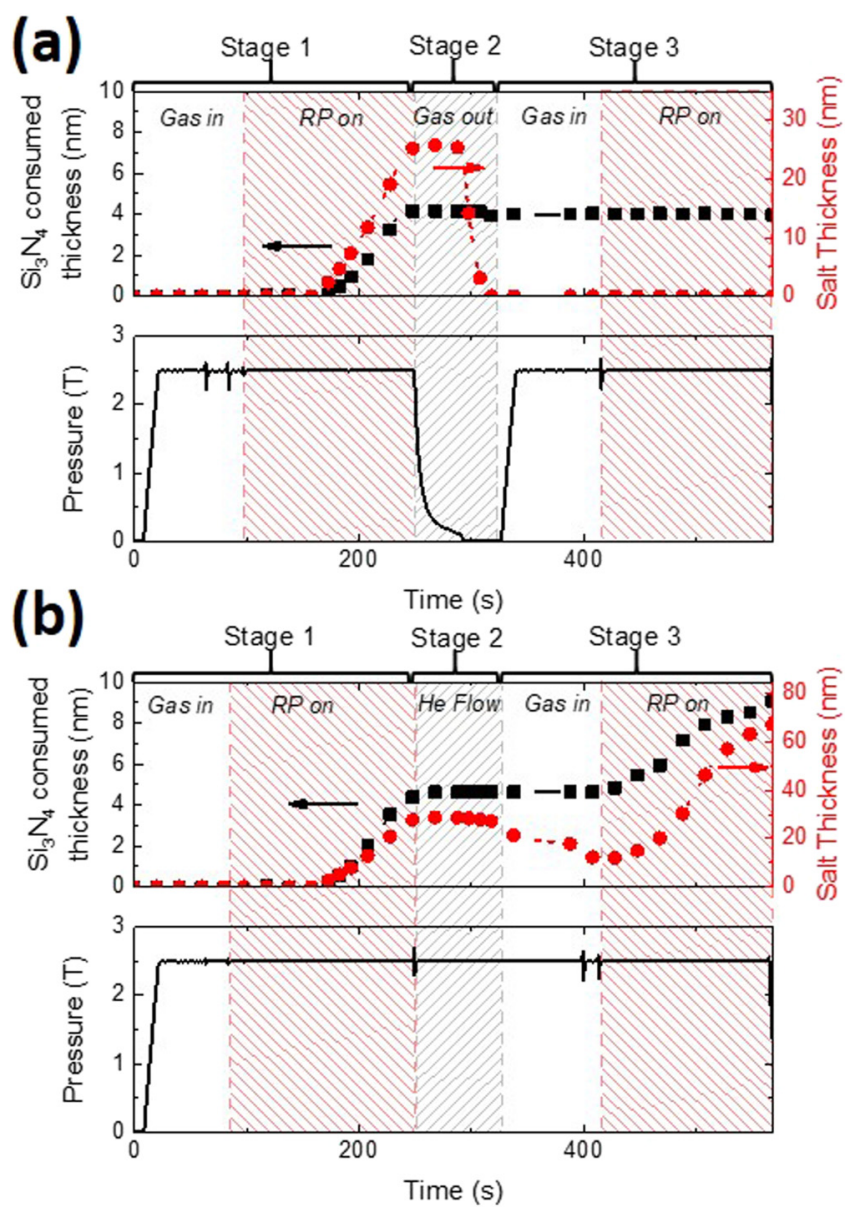

FIG. 8. Kinetics of the pristine $\mathrm{Si}_{3} \mathrm{~N}_{4}$ film consumption (black square) and salt formation (red circle) during a three-stage process. Stages 1 and 3 are similar and correspond to the $\mathrm{NH}_{3} / \mathrm{NF}_{3} / \mathrm{He} \mathrm{RP}$ process at 2.5 Torr comprising a stabilization step where the gas are introduced and the pressure in the chamber increases up to the operating pressure (Gas in-white area), followed by the RP source ON step (red dashed area). Stage 2 (dark dashed dark area) corresponds to (a) a Gas phase evacuation step and (b) a He stabilization step at 2.5 Torr. For both (a) and (b), the pressure in the reactor is also presented (black line) along with the wafer temperature. 
the He flow is supplied to maintain the chamber pressure at 2.5 Torr.

During the first $\mathrm{RP}$ on stage, $\mathrm{Si}_{3} \mathrm{~N}_{4}$ is etched as expected through the growth of a salt layer for both experiments. The salt layer reaches a thickness of $25.8 \mathrm{~nm}$ for an $\mathrm{Si}_{3} \mathrm{~N}_{4}$ consumed thickness of $4.2 \mathrm{~nm}$. However, during the second stage, Fig. 8 shows that the salt layer desorbs almost instantly as the chamber pressure decreases below $10 \mathrm{mT}$ in experiment 1 , while it remains on the substrate if the chamber pressure is kept constant at 2.5 Torr in experiment 2. This means that in experiment 1 , the pressure in stage 2 decreases below the saturation vapor pressure of the salt at $100{ }^{\circ} \mathrm{C}$, allowing the salt to desorb. Moreover, during the second $\mathrm{RP}$ on stage (stage 3 ), no salt growth and consequently no $\mathrm{Si}_{3} \mathrm{~N}_{4}$ etching is observed in experiment 1 , while $\mathrm{Si}_{3} \mathrm{~N}_{4}$ etching proceeds normally with the formation of the salt layer in experiment 2 without incubation time. Those two experiments highlight two phenomena. First, experiment 1 confirms the trend of Fig. 7(a) that the $\mathrm{Si}_{3} \mathrm{~N}_{4}$ surface oxidation state plays a role in the etching reaction ignition since the $\mathrm{Si}_{3} \mathrm{~N}_{4}$ surface is oxidized at the beginning of the first RP on stage and deoxidized at the beginning of the second RP on stage. Secondly, experiment 2 shows that if a salt layer remains on the $\mathrm{Si}_{3} \mathrm{~N}_{4}$ surface when the RP is turned off and on, the reaction goes on as if there was no interruption since the $70 \mathrm{~s}$ incubation time of stage 1 is not observed during stage 3 . This suggests that the deposited film contains some etching species for the $\mathrm{Si}_{3} \mathrm{~N}_{4}$ film.

\section{Discussion on the etching mechanisms of $\mathrm{Si}_{3} \mathrm{~N}_{4}$ films exposed to $\mathrm{NH}_{3} / \mathrm{NF}_{3}$ remote plasma}

In the literature, a reaction scheme has been proposed for the etching of $\mathrm{SiO}_{2}$ films exposed to $\mathrm{NF}_{3} / \mathrm{NH}_{3}$ or $\mathrm{NF}_{3} / \mathrm{H}_{2}$ remote plasma, but very little has been reported for $\mathrm{Si}_{3} \mathrm{~N}_{4}$. It is suggested that $\mathrm{NH}_{4} \mathrm{~F}$ and $\mathrm{HF}$ reactants are formed in the $\mathrm{NH}_{3} / \mathrm{NF}_{3}$ remote plasma chamber by $\mathrm{NF}_{3}$ (respectively $\mathrm{NH}_{3}$ ) dissociation into $\mathrm{NF}_{x}$ $(x=1-2)$ and $\mathrm{F}$ [respectively $\mathrm{NH}_{x}(x=1-2)$ and $\mathrm{H}$ ] and subsequent recombination of these fragments together and with the feed gases, as described by Eqs. (2)-(5), ${ }^{17,23-25}$

$$
\begin{gathered}
\mathrm{NF}_{3} \rightarrow \mathrm{NF}_{2}+\mathrm{F}, \\
\mathrm{NH}_{3} \rightarrow \mathrm{NH}_{2}+\mathrm{H}, \\
\mathrm{H}+\mathrm{F} \rightarrow \mathrm{HF}, \\
\mathrm{NH}_{3}+\mathrm{HF} \rightarrow \mathrm{NH}_{4} \mathrm{~F} .
\end{gathered}
$$

Because of the high electronegativity of the $\mathrm{F}$ atom, $\mathrm{F}$ in the $\mathrm{NH}_{4} \mathrm{~F}$ and $\mathrm{HF}$ molecules is negatively charged while $\mathrm{NH}_{4}$ and $\mathrm{H}$ are positively charged. Similarly, $\mathrm{O}$ and $\mathrm{Si}$ of $\mathrm{SiO}_{2}$ are negatively and positively charged, respectively. $\mathrm{F}$ will then preferentially attack positively charged $\mathrm{Si}$ atoms while $\mathrm{H}$ and $\mathrm{NH}_{4}$ are attracted to $\mathrm{O}$ through a Coulomb force. These interactions weaken both $\mathrm{Si}-\mathrm{O}$ and $\mathrm{H}-\mathrm{F}$ bonds and results in $\mathrm{Si}-\mathrm{F}$ bond formation. The released negatively charged oxygen atoms combine with $\mathrm{H}$ to generate $\mathrm{H}_{2} \mathrm{O}$ [cf. Eq. (6)]. The resultant etching products, such as $\mathrm{SiF}_{4}$, react with $\mathrm{NH}_{4} \mathrm{~F}$ and change into the final product $\left(\mathrm{NH}_{4}\right)_{2} \mathrm{SiF}_{6}$ as described by Eqs. (6)-(8). ${ }^{17,18,24,25}$ Hayashi et al. ${ }^{35}$ suggests that the reactants are adsorbed on the wafer surface, on which a condensed phase is formed, so that a type of ammonium fluoride etching in the liquid phase takes place,

$$
\begin{gathered}
\mathrm{SiO}_{2}+4 \mathrm{HF} \rightarrow \mathrm{SiF}_{4}+2 \mathrm{H}_{2} \mathrm{O}, \\
\mathrm{SiF}_{4}+2 \mathrm{NH}_{4} \mathrm{~F} \rightarrow\left(\mathrm{NH}_{4}\right)_{2} \mathrm{SiF}_{6}, \\
\mathrm{SiO}_{2}+2 \mathrm{NH}_{4} \mathrm{~F}+4 \mathrm{HF} \rightarrow\left(\mathrm{NH}_{4}\right)_{2} \mathrm{SiF}_{6}+2 \mathrm{H}_{2} \mathrm{O} .
\end{gathered}
$$

In the case of $\mathrm{Si}_{3} \mathrm{~N}_{4}$, Knolle and Huttemann observed that the formation of a $\left(\mathrm{NH}_{4}\right)_{2} \mathrm{SiF}_{6}$ layer (and thus the etching of the $\mathrm{Si}_{3} \mathrm{~N}_{4}$ film) when exposed to a $\mathrm{CF}_{4}$ plasma (remote ICP) occurs only if its surface is hydrogenated and oxidized. ${ }^{36}$ This suggests that the presence of $\mathrm{SiO}$ bonds favor the chemical reaction.

It is also interesting to note that the etching of pristine $\mathrm{Si}_{3} \mathrm{~N}_{4}$ films exposed to the $\mathrm{NH}_{3} / \mathrm{NF}_{3}$ remote plasma at 2.5 Torr drastically slows down with increasing temperature and even stops above $120^{\circ} \mathrm{C}$ (cf. Fig. 9). This etch trend with temperature is quite unusual for a pure chemical type of etching that generally displays an Arrhenius dependence on the temperature. ${ }^{37}$ On the contrary, the temperature dependence observed is well consistent with the theory of chemisorption kinetics. ${ }^{38}$ As theoretically or experimentally reported, ${ }^{38,39}$ when gaseous molecules or atoms collide with a surface, they may first adsorb on the surface in a physisorbed precursor state, which acts as a reservoir for the subsequent adsorption into a chemisorbed state. The fraction of the impinging molecules that is finally chemisorbed results from the competition between two processes: the incorporation of physically adsorbed molecules into a chemisorbed layer, on the one hand, and their evaporation into the surrounding gas, on the other hand. The dependence of the chemisorption rate on the temperature is determined by the difference in the activation energy of these two processes. In our case, it is likely that the activation barrier for the desorption of

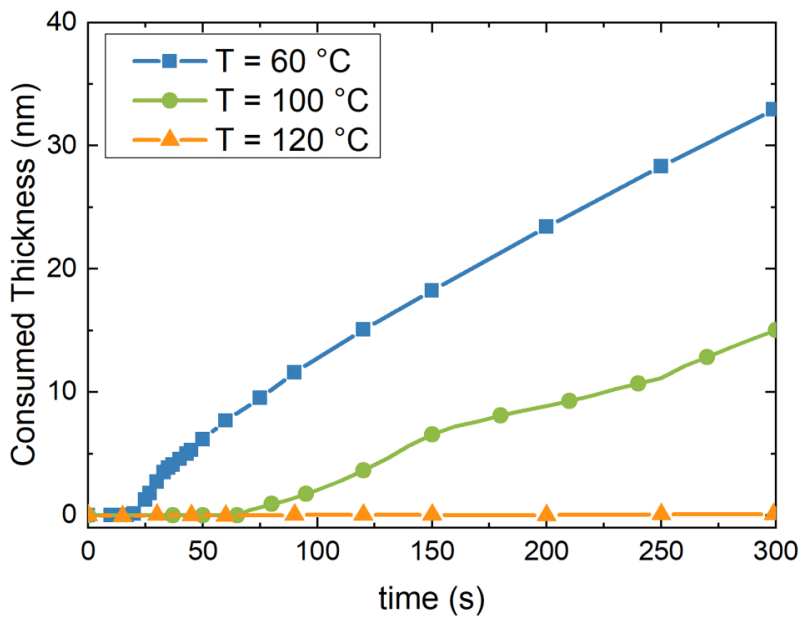

FIG. 9. Etching kinetics of $\mathrm{Si}_{3} \mathrm{~N}_{4}$ film at 60 (blue square), 100 (green circle), and $120^{\circ} \mathrm{C}$ (orange triangle) in $\mathrm{He} / \mathrm{NH}_{3} / \mathrm{NF}_{3}$ plasma. 


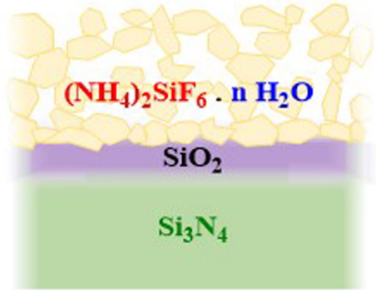

$\mathrm{NH}_{4} \mathrm{~F}$ and HF reactants is greater than the one of their chemisorption, implying that a rise in temperature rapidly leads in a depopulation of the physisorbed layer that cannot be compensated by the enhanced chemisorption with temperature. This results in an increase of the incubation period and a decrease of the etch rate with increasing temperature (cf. Fig. 9).

The etch kinetics of pristine and HF-deoxidized $\mathrm{Si}_{3} \mathrm{~N}_{4}$ at the given process temperature of $100^{\circ} \mathrm{C}$ shown in Fig. 7 clearly indicates that the adsorption step is the rate limiting step of the reaction and suggests that the presence of $\mathrm{Si}-\mathrm{O}$ rather than $\mathrm{Si}-\mathrm{N}$ bonds lowers the activation barrier for the dissociative chemisorption. In a pure chemical process, etch rates are determined by the chemical bond strength that holds the material together. The ratedetermining step is then the breaking of the first $\mathrm{Si}-\mathrm{N}$ bond (or more precisely the $\mathrm{Si}-\mathrm{NH}_{2}$ terminated surface) in the case of HF-deoxidized $\mathrm{Si}_{3} \mathrm{~N}_{4}$ or $\mathrm{Si}-\mathrm{O}$ bond (more precisely the $\mathrm{Si}-\mathrm{OH}$ terminated surface) and its substitution into $\mathrm{Si}-\mathrm{F}$ bond. The $\mathrm{Si}-\mathrm{O}$ bond $(799 \mathrm{~kJ} / \mathrm{mol})$ is stronger than the $\mathrm{Si}-\mathrm{N}$ bond $(470 \mathrm{~kJ} / \mathrm{mol})$, which suggests that the activation barrier for the chemisorption should be higher in the case of $\mathrm{SiO}_{\mathrm{x}}$ surface. In fact, Knotter et al. showed that in $\mathrm{HF}_{2-}\left(\mathrm{F}-\mathrm{H}^{\cdots}: \mathrm{F}^{-}\right)$environment (equivalent to our $\mathrm{NH}_{4}^{+} \mathrm{F}^{-}: \cdots \mathrm{H}-\mathrm{F}$ physisorbed layer), there is a site path for replacing the $\mathrm{OH}$ by $\mathrm{F}$ in which the $\mathrm{Si}-\mathrm{OH}$ bond does not have to be broken first. $^{40,41}$ This path lowers the activation barrier of the chemisorption step compared to the case of $\mathrm{SiN}$ system in which the $\mathrm{Si}-\mathrm{N}$ bond needs to be broken first.
This mechanism could explain why the etching starts on the pristine $\mathrm{SiN}$ and not on the deoxidized substrate. Moreover, once the etching has started, the water formed upon the reaction of $\mathrm{NH}_{4} \mathrm{~F}$ and $\mathrm{HF}$ with the native $\mathrm{SiO}_{2}$ present at the surface of the $\mathrm{Si}_{3} \mathrm{~N}_{4}$ [cf. Eq. (8)] remains in the ammonium fluorosilicate layer as a hydrate and can further react with $\mathrm{Si}_{3} \mathrm{~N}_{4}$ underneath to form new $\mathrm{SiO}$ bonds [cf. Eq. (9)],

$$
\mathrm{Si}_{3} \mathrm{~N}_{4}+6 \mathrm{H}_{2} \mathrm{O} \rightarrow 3 \mathrm{SiO}_{2}+4 \mathrm{NH}_{3} .
$$

The proposed mechanism is illustrated in Fig. 10. It emphasizes the role of oxygen as a surface oxidant that allows the reaction to be pursued.

However, Knotter et al. showed that once the first SiF bond is formed, the activation barrier to break a new adjacent $\mathrm{SiN}$ bond is lower because of the stronger polarization of the $\mathrm{SiF}$ bond with respect to the SiN bond. The Si center becomes prone to a nucleophile attack by the HF molecule as illustrated in Fig. 11. The SiN bond is broken and replaced by $\mathrm{SiF}$ and the nitrogen atom is protonated. This mechanism is repeated three times until forming the reactions products $\mathrm{SiF}_{4}$ and $\mathrm{NH}_{3}$ [cf. Eq. (10)]. $\mathrm{SiF}_{4}$ can further react with $\mathrm{NH}_{4} \mathrm{~F}$ to form the salt layer [Eq. (11)], the balance equation being given in Eq. (12) as

$$
\mathrm{Si}_{3} \mathrm{~N}_{4}+12 \mathrm{HF} \rightarrow 3 \mathrm{SiF}_{4}+4 \mathrm{NH}_{3}
$$

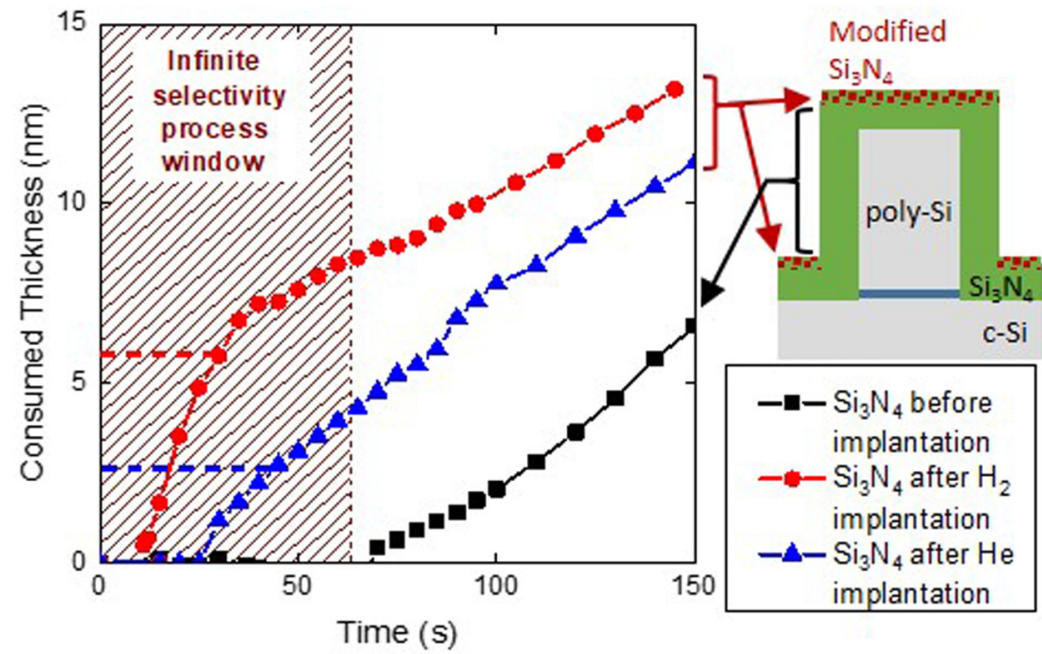

FIG. 11. Schematic representation of a substitution reaction to free the Si-F unit. 


$$
\begin{gathered}
\mathrm{SiF}_{4}+2 \mathrm{NH}_{4} \mathrm{~F} \rightarrow\left(\mathrm{NH}_{4}\right)_{2} \mathrm{SiF}_{6}, \\
\mathrm{Si}_{3} \mathrm{~N}_{4}+6 \mathrm{NH}_{4} \mathrm{~F}+12 \mathrm{HF} \rightarrow 3\left(\mathrm{NH}_{4}\right)_{2} \mathrm{SiF}_{6}+4 \mathrm{NH}_{3} .
\end{gathered}
$$

\section{Implanted vs nonimplanted $\mathrm{Si}_{3} \mathrm{~N}_{4}$}

Figure 12 compares the etch kinetics of pristine and implanted $\mathrm{Si}_{3} \mathrm{~N}_{4}$ films when exposed to $\mathrm{NH}_{3} / \mathrm{NF}_{3} / \mathrm{He}$ remote plasma process at $100{ }^{\circ} \mathrm{C}$. The $\mathrm{Si}_{3} \mathrm{~N}_{4}$ films are HF-deoxidized prior the implantation, while the pristine $\mathrm{Si}_{3} \mathrm{~N}_{4}$ film still has its native oxide. The ellipsometric data of implanted $\mathrm{Si}_{3} \mathrm{~N}_{4}$ are also fitted with a bilayer model using similar salt dispersion law to the one used for the pristine materials. It is observed that the incubation time is considerably reduced for implanted $\mathrm{Si}_{3} \mathrm{~N}_{4}$ films, the etching starting after $11 \mathrm{~s}$ and $27 \mathrm{~s}$ for $\mathrm{H}_{2}$ and $\mathrm{He}$ implantation, respectively, against $70 \mathrm{~s}$ for the pristine $\mathrm{Si}_{3} \mathrm{~N}_{4}$. It should be noted that the incubation time are reproducible at $\pm 5 \mathrm{~s}$.

Based on the etching mechanism proposed in Sec. III B 2, we believe that the oxygen incorporated into the $\mathrm{Si}_{3} \mathrm{~N}_{4}$ film by the implantation step acts as a catalyst of the reaction between the plasma reactants and $\mathrm{Si}_{3} \mathrm{~N}_{4}$. But its presence only cannot explain the lower incubation time observed for $\mathrm{H}_{2}$ and $\mathrm{He}$ implantation compared to the $\mathrm{Si}_{3} \mathrm{~N}_{4}$ film with its native oxide, since the oxygen content at the top surface is higher for pristine $\mathrm{Si}_{3} \mathrm{~N}_{4}$ film (cf. Fig. 4). The disorder introduced by the implantation in the $\mathrm{Si}_{3} \mathrm{~N}_{4}$ films may also play a role. From the XRR measurements, the top oxide layer generated by the implantation is less dense than a native oxide. The dangling bonds and porosity created by the implantation may favor the physisorption and the subsequent chemisorption of the neutral reactive species. We also noticed that for any implantation or RP process conditions, the incubation time is always lower for $\mathrm{H}_{2}$ implantation than $\mathrm{He}$ implantation suggesting that $\mathrm{H}$-terminal bonds could constitute favorable attack sites.

In the $\mathrm{He}$ case, once the etch starts, the $\mathrm{Si}_{3} \mathrm{~N}_{4}$ consumed thickness evolves linearly with the processing time and the etch

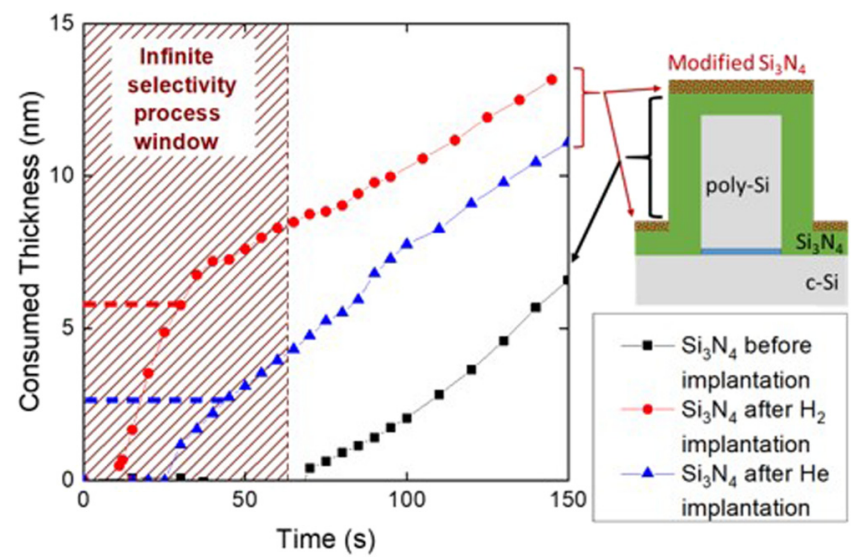

FIG. 12. Etching kinetics of deoxidized $\mathrm{Si}_{3} \mathrm{~N}_{4}$ film after $\mathrm{H}_{2}$ (red circle) and $\mathrm{He}$ (blue triangle) implantation as well as pristine $\mathrm{Si}_{3} \mathrm{~N}_{4}$ film (black square) in $\mathrm{He} / \mathrm{NH}_{3} / \mathrm{NF}_{3}$ plasma at $100^{\circ} \mathrm{C}$. kinetics are similar to the ones of the $\mathrm{Si}_{3} \mathrm{~N}_{4}$ pristine film $\left(5.0 \times 10^{-2} \mathrm{~nm} / \mathrm{s}\right)$. On the contrary, in the $\mathrm{H}_{2}$ implantation case, a change of the etch kinetics is observed at the depth corresponding to the modified layer thickness measured by XRR. This transition occurs after a $6 \mathrm{~nm}$ etch depth. It is also noticed that once the modified layer is etched, the $\mathrm{Si}_{3} \mathrm{~N}_{4}$ film is etched with similar etch kinetics to the ones of the pristine $\mathrm{Si}_{3} \mathrm{~N}_{4}$ film. The etch kinetics of the modified layer by $\mathrm{H}_{2}$ implantation $\left(2.9 \times 10^{-1} \mathrm{~nm} / \mathrm{s}\right)$ is higher than the ones of the pristine and He-implanted $\mathrm{Si}_{3} \mathrm{~N}_{4}$ films $\left(5.0 \times 10^{-2} \mathrm{~nm} / \mathrm{s}\right)$ allowing a selectivity of modified $\mathrm{Si}_{3} \mathrm{~N}_{4}$ after a $\mathrm{H}_{2}$ implantation over nonmodified $\mathrm{Si}_{3} \mathrm{~N}_{4}$ of 5.8. The higher etch rate for the $\mathrm{H}_{2}$ implanted $\mathrm{Si}_{3} \mathrm{~N}_{4}$ layer goes along with a slight decrease of the salt porosity (with a void of $75 \%$ against $80 \%$ for pristine and $\mathrm{He}$ damaged $\mathrm{Si}_{3} \mathrm{~N}_{4}$ films) and the correlation coefficient is less important (4.2 vs 6.1). Once the $\mathrm{H}_{2}$ implanted $\mathrm{Si}_{3} \mathrm{~N}_{4}$ layer is etched, the coefficient and the void percentage of the pristine $\mathrm{Si}_{3} \mathrm{~N}_{4}$ are recovered.

In the steady-state regime, once the etching is initiated, there is in final no etch selectivity between the top modified layer by the He implantation over the pristine $\mathrm{Si}_{3} \mathrm{~N}_{4}$ material, while a low etch selectivity of about 5.8 is expected in the $\mathrm{H}_{2}$ implantation case. This selectivity is the same as the one of 6 found by Posseme et al. ${ }^{17}$ for $\mathrm{Si}_{3} \mathrm{~N}_{4}$ removal using $\mathrm{NH}_{3} / \mathrm{NF}_{3}$ remote plasma, which is not satisfying for the spacer etch process application and is far below the selectivity of 31 achieved using $20 \%$ HF gas. $^{15,16}$

These results suggest that the hydrogen incorporation into the $\mathrm{Si}_{3} \mathrm{~N}_{4}$ film is thermodynamically favorable for the salt formation and thus the $\mathrm{Si}_{3} \mathrm{~N}_{4}$ consumption.

We think the etching mechanisms of implanted $\mathrm{Si}_{3} \mathrm{~N}_{4}$ are similar to the the ones illustrated in Fig. 11 and Eqs. (10)-(12). The main difference resides in the number of $\mathrm{SiN}$ units to break, which is the rate limiting step. Martirosyan et al. ${ }^{34}$ have shown with their dynamic molecular simulation that the amount of $\mathrm{SiN}$ bonds broken by $\mathrm{He}$ implantation is lower than for $\mathrm{H}_{2}$ implantation, which is consistent with the higher density of the modified layer by He implantation predicted by XRR (cf. Fig. 3). The damage generated by the He implantation may not be sufficient to see a significant difference in the etching kinetics compared to the pristine material. It may just activate the etching, thanks to $\mathrm{O}$ incorporation and formation of dangling bonds.

On the other side, as mentioned in Sec. III A, $\mathrm{H}_{2}$ implantation results in the formation of $\mathrm{SiH}_{\mathrm{x}}$ and $\mathrm{NH}$ bonds, meaning that the $\mathrm{Si}_{3} \mathrm{~N}_{4}$ network is broken with less $\mathrm{Si}-\mathrm{N}$ units. The $\mathrm{SiH}_{\mathrm{x}}$ units present in the $\mathrm{H}_{2}$ implanted layer are more easily transformed into $\mathrm{SiF}_{\mathrm{x}}$ than $\mathrm{SiN}_{\mathrm{x}}$ bonds in the pristine materials for thermodynamical reasons. Moreover, some nitrogen atoms are already protonated, which is favorable for the formation of the $\mathrm{NH}_{3}$ etch by-products.

Finally, Fig. 11 demonstrates that the functionalization of the $\mathrm{Si}_{3} \mathrm{~N}_{4}$ surface by implantation activates the chemical reaction between the $\mathrm{Si}_{3} \mathrm{~N}_{4}$ film and the reactants present in the diffusion chamber and considerably reduces the incubation time. This offers a process window during which the implanted $\mathrm{Si}_{3} \mathrm{~N}_{4}$ is etched with infinite selectivity over the pristine $\mathrm{Si}_{3} \mathrm{~N}_{4}$, which corresponds to the process duration that is inferior to the pristine $\mathrm{Si}_{3} \mathrm{~N}_{4}$ incubation time (about $70 \mathrm{~s}$ ). This phenomenon can be exploited in a two-step cycling process comprising implantation and remote plasma etching steps to make topographically selective etching as discussed below in Sec. III C. 


\section{Two-step cycling etching for topographically selective etching}

The current trend in atomic layer deposition (ALD) is to cycle a selective functionalization step and deposition step to make topographically $^{42}$ or chemical ${ }^{43}$ selective deposition. The concept is based on the fact that the deposition characteristics depend on the surface properties of the employed substrate. ${ }^{44}$ The functionalization step is aimed to chemically and locally modify the surface of one material with respect to the other surfaces in order to inhibit or activate reactive sites and then prevent or catalyze further reactions between the ALD precursor molecules and the functionalized surface. In our case, it happens that remote plasma processes whose etching mechanisms rely on the chemical action of plasma neutrals are also very sensitive to the chemistry of the substrate. The implantation step will functionalize the horizontal surfaces selectively over the vertical surfaces, thanks to the ion anisotropy (cf. Fig. 12). During the subsequent short RP etching step $(<70 \mathrm{~s})$, the etching will be activated on horizontal surfaces while vertical surfaces will not be consumed. The two steps will be repeated until etching the desired horizontal surface thickness.

Figure 13(a) shows a 6 cycle etching of blanket $\mathrm{Si}_{3} \mathrm{~N}_{4}$ with its native oxide alternating a $60 \mathrm{~s} \mathrm{H}_{2}$ implantation step followed by a $30 \mathrm{~s} \mathrm{NH}_{3} / \mathrm{NF}_{3} / \mathrm{He}$ remote plasma at $100{ }^{\circ} \mathrm{C}$. The plasma conditions are the same as the ones described in Sec. II. Note that the CCP step is performed at 50 mTorr, while the RP step at 2.5 Torr, implying that pressure stabilization steps between those two steps are required.

From Fig. 13(a), the $\mathrm{Si}_{3} \mathrm{~N}_{4}$ consumed thickness at each cycle can be estimated, comprising the part coming from the sputtering occurring during the implantation and the part coming from the RP etching [cf. Fig. 13(b)]. It is observed that the total removed thickness at each cycle is reproducible and of $4.5 \mathrm{~nm} \pm 0.5 \mathrm{~nm}$. The thickness removed during the RP step varies slightly from one cycle to another $( \pm 0.5 \mathrm{~nm})$. This variability of the RP step is mainly attributed to the variability of the incubation time $(15 \mathrm{~s} \pm 5 \mathrm{~s})$. Consistent with the results shown in Fig. 3, there is no sputtering during the implantation step of the first cycle, while the subsequent cycles show between $0.5 \mathrm{~nm}$ and $1 \mathrm{~nm}$ of sputtering during the implantation. Although the salts are outgassed after the RP step, XPS analyses reveal that a rich in fluorine reactive layer $(9 \%$ of the total atomic concentration) is left on the $\mathrm{Si}_{3} \mathrm{~N}_{4}$ surface after the RP step [cf. Fig. 13(c)]. This layer has a thickness of $0.7 \mathrm{~nm}$ and remains constant at each cycle. We suspect that this layer is easily chemically sputtered by $\mathrm{H}$ ions during the subsequent implantation explaining why sputtering is observed for all cycles except for the first one.

To simulate what could happen on $\mathrm{Si}_{3} \mathrm{~N}_{4}$ vertical surfaces (spacer sidewalls), a $\mathrm{Si}_{3} \mathrm{~N}_{4}$ film with its native oxide is exposed to cycles of a two-step process comprising an $\mathrm{H}_{2}$ gas step (using the $\mathrm{H}_{2}$ implantation conditions except that the source is turned off) followed by the $30 \mathrm{~s} \mathrm{RP}$ step at $100^{\circ} \mathrm{C}$. Figure 13 (a) shows that the $\mathrm{Si}_{3} \mathrm{~N}_{4}$ film exposed to this cycling process is not etched, meaning that in these conditions, 6 cycles of $30 \mathrm{~s}$ RP step is not equivalent to $180 \mathrm{~s}$ continuous etching RP process [see Fig. 7(a)]. Indeed, the reactive species that adsorb to the $\mathrm{Si}_{3} \mathrm{~N}_{4}$ surface during the $30 \mathrm{~s} R$ step, but have not reacted yet, are outgassed during the next low-

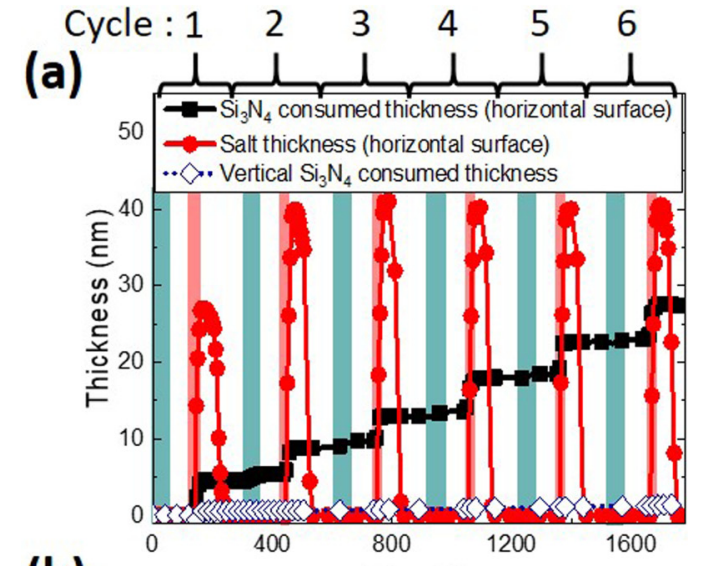

(b)

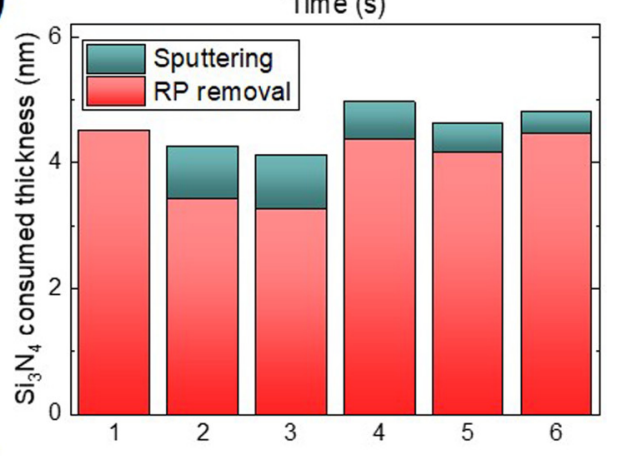

(c)

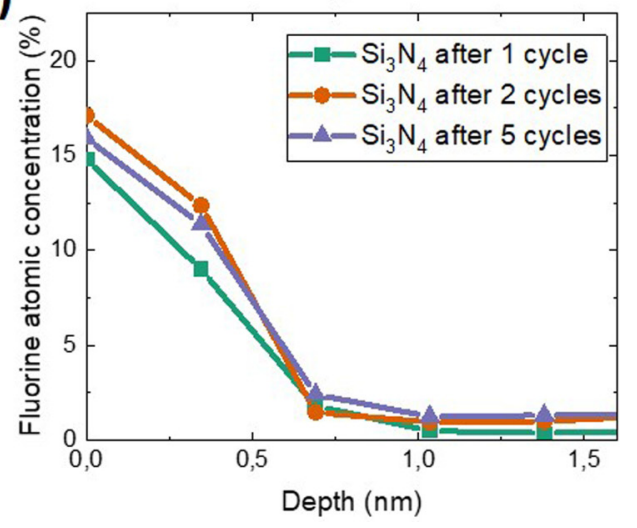

FIG. 13. (a) $\mathrm{Si}_{3} \mathrm{~N}_{4}$ consumed (black square) and salt layer (red circle) thicknesses evolution during a 6 cycle etching alternating $60 \mathrm{~s}$ of $\mathrm{H}_{2}$ implantation and $30 \mathrm{~s}$ of $\mathrm{NH}_{3} / \mathrm{NF}_{3} / \mathrm{He}$ remote plasma at $100^{\circ} \mathrm{C}$ compared to the etch kinetics of a $\mathrm{Si}_{3} \mathrm{~N}_{4}$ film exposed to the alternate of $\mathrm{H}_{2}$ gas step followed by $30 \mathrm{~s}$ of $\mathrm{NH}_{3} /$ $\mathrm{NF}_{3} / \mathrm{He}$ remote plasma simulating vertical $\mathrm{Si}_{3} \mathrm{~N}_{4}$ surface (blue empty diamond). (b) Consumed $\mathrm{Si}_{3} \mathrm{~N}_{4}$ thickness per cycle. (c) ARXPS depth profile of the fluorine atomic concentration after 1,2 , and 5 cycles.

pressure gas step. This resets the incubation time of the RP step to zero at each cycle.

It is a promising result for the spacer process application where it is expected that the spacer sidewalls behave similarly. 


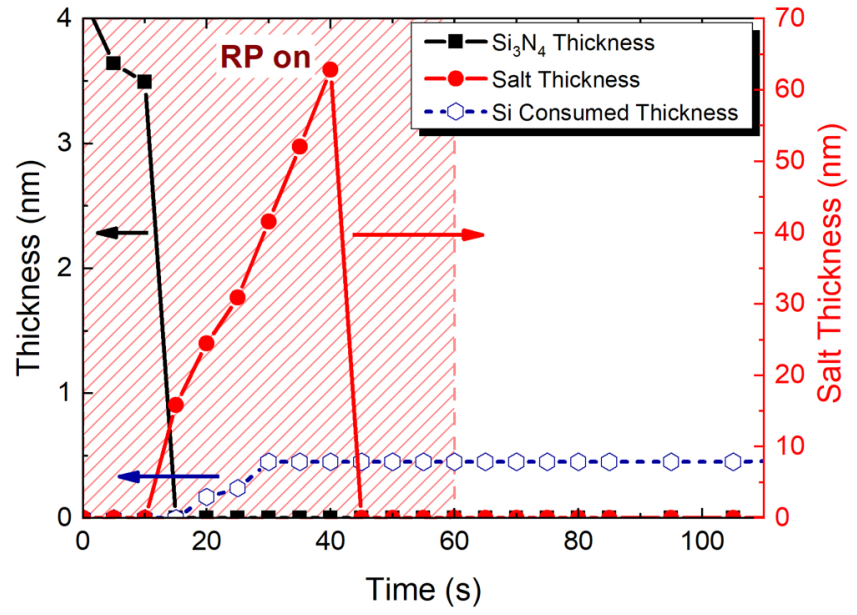

FIG. 14. $\mathrm{Si}_{3} \mathrm{~N}_{4}$ film thickness (black square) vs $\mathrm{Si}$ consumed thickness (blue diamond) during the 6th and last cycle that stops on the Si surface. The RP is maintained ON during $60 \mathrm{~s}$ containing $45 \mathrm{~s}$ of overetch.
However, in the real cycling process, the $\mathrm{Si}_{3} \mathrm{~N}_{4}$ sidewalls are also bombarded by $\mathrm{H}$ ions at grazing incidence and reactive $\mathrm{H}$ radicals during the implantation. The impact of $\mathrm{H}$ radicals can reasonably be neglected since Thedjoisworo et al. ${ }^{45}$ show that below $150{ }^{\circ} \mathrm{C}$, the etch rate of $\mathrm{Si}_{3} \mathrm{~N}_{4}$ film exposed to $\mathrm{H}$ radicals produced by downstream plasma are extremely low (below $0.18 \mathrm{~A} / \mathrm{min}$ ). On the contrary, the scattering of hydrogen ions produced in the capacitive discharge cannot be ignored. From the work by Donkò et al. that investigates the ion properties in low-pressure oxygen CCPs, ${ }^{46}$ it is expected that in the plasma conditions we used for the $\mathrm{H}_{2}$ implantation ( $50 \mathrm{mTorr}, 120 \mathrm{eV}$ ion energy), most of the ions arrive at angles smaller than $3^{\circ}$ meaning that the pattern sidewalls are indeed subjected to ionic bombardment. The ion flux received on the sidewalls may be enough to functionalize the vertical surface and activate its etching without incubation time, which is detrimental for the infinite etch selectivity expected between implanted and nonimplanted $\mathrm{Si}_{3} \mathrm{~N}_{4}$. However, the ion dose deviated on the sidewalls will be lower than the one received on horizontal surfaces and certainly not sufficient to induce a fully modified $\mathrm{H}$ rich layer. Kumakura et al. ${ }^{47}$ have shown that the etching rate of the $\mathrm{H}_{2}$ implanted surface layer depends on the $\mathrm{H}$ ion dose. It increases
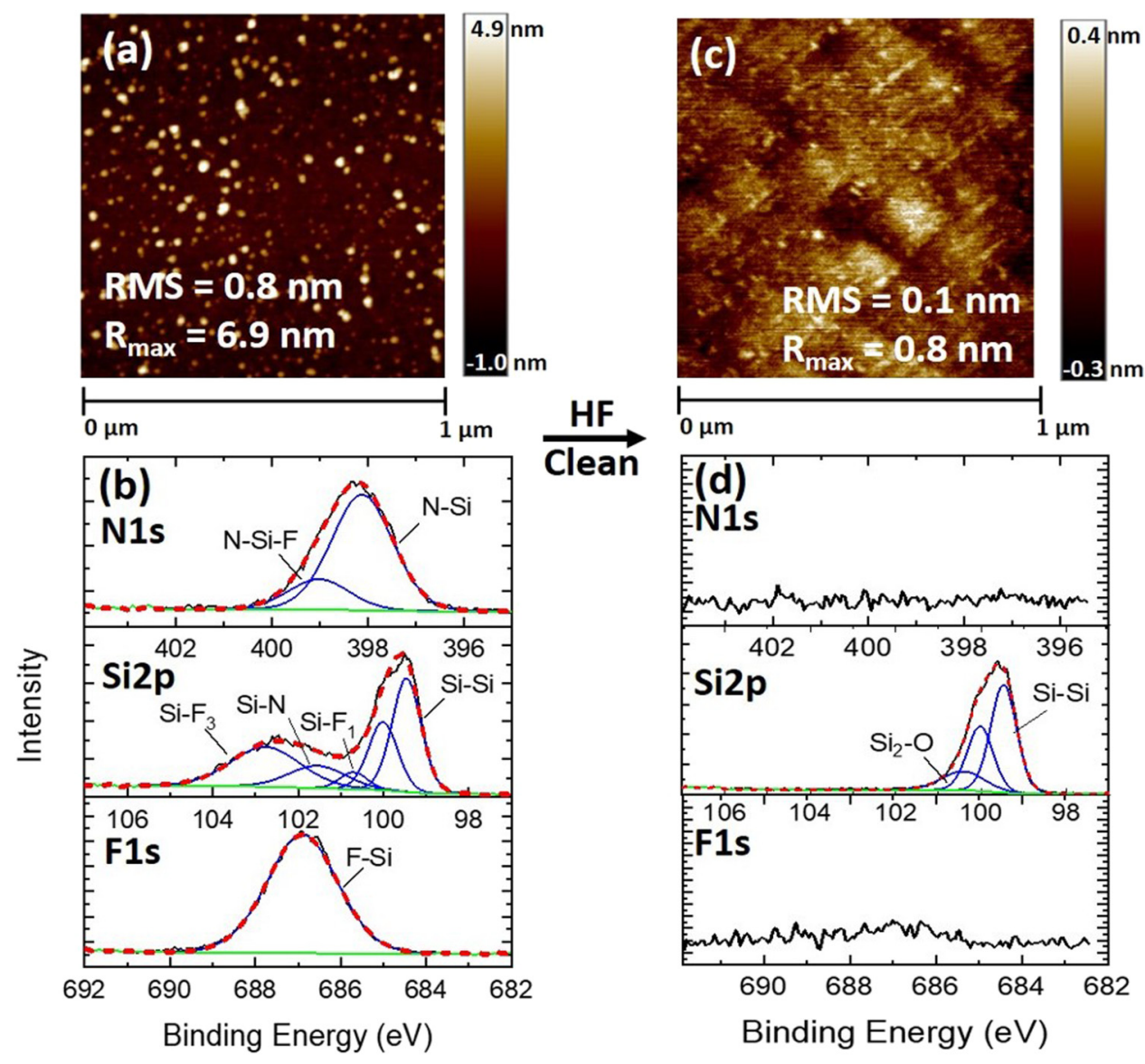

FIG. 15. Surface roughness measured by AFM and XPS spectra of Si surfaces exposed to $\mathrm{NH}_{3} / \mathrm{NF}_{3} \mathrm{RP}$ at $100^{\circ} \mathrm{C}$ [(a) and (b)] before and [(c) and (d)] after a HF clean. 
with the incorporated $\mathrm{H}$ dose until reaching saturation above a certain ion dose threshold. This means that if the etch is activated on the sidewalls, the $\mathrm{Si}_{3} \mathrm{~N}_{4}$ etch kinetics will be lower than on the fully $\mathrm{H}$ - modified horizontal surfaces. In such case, it is expected that the etch kinetics of the sidewalls are similar to the He-implanted or pristine $\mathrm{Si}_{3} \mathrm{~N}_{4}$ ones, implying an etch selectivity of only 5.8 between horizontal and vertical surfaces. If this should happen, then the operating conditions of the $\mathrm{NH}_{3} / \mathrm{NF}_{3}$ remote plasma should be readjusted for higher etch selectivity to be obtained between $\mathrm{H}_{2}$ implanted $\mathrm{Si}_{3} \mathrm{~N}_{4}$ and pristine $\mathrm{Si}_{3} \mathrm{~N}_{4}$.

Finally, Fig. 14 shows what happens at the 6th cycle when the $\mathrm{Si}_{3} \mathrm{~N}_{4}$ layer is entirely consumed and the process is stopped on the underneath Si surface. We added $45 \mathrm{~s}$ of overetch in the remote plasma to observe the selectivity of the $\mathrm{Si}_{3} \mathrm{~N}_{4}$ film over the underlying silicon. As soon as $\mathrm{Si}_{3} \mathrm{~N}_{4}$ is entirely consumed by the salt formation and the Si surface is reached, the salt layer outgassed and the ellipsometric data indicate that only $0.5 \mathrm{~nm}$ of $\mathrm{Si}$ is consumed even for very long processing time of RP last step. In fact, this consumption is attributed to the consumption of the native silicon oxide present between the $\mathrm{Si}_{3} \mathrm{~N}_{4}$ and $\mathrm{Si}$ layer. AFM and XPS analyses performed on Si surfaces at the end of the 6 cycle process are shown in Fig. 15. The AFM image reveals the presence of some residues on the $\mathrm{Si}$ surface that are identified by XPS as salt residues or $\mathrm{Si}_{3} \mathrm{~N}_{4}$ residues [cf. Figs. 15(a) and 15(b)]. Indeed, the Si2p peak is decomposed with 4 contributions: a peak at $99.4 \mathrm{eV}$ attributed to $\mathrm{Si}-\mathrm{Si}$ bonds, a peak at $101.7 \mathrm{eV}$ attributed to $\mathrm{Si}-\mathrm{N}$ bonds, and two peaks at $100.7 \mathrm{eV}$ and $102.7 \mathrm{eV}$ attributed to $\mathrm{SiF}_{1}$ and $\mathrm{SiF}_{3}$ bonds. The latter are confirmed by the presence of $\mathrm{Si}-\mathrm{F}$ and $\mathrm{N}-\mathrm{F}$ bonds on the N1s and F1s spectra. On the F1s spectra, Si-F bond contributions are detected at $687.8 \mathrm{eV}$. Concerning the N1s spectra, two contributions are detected: $\mathrm{N}-\mathrm{Si}$ bonds at $397.5 \mathrm{eV}$ and $\mathrm{N}-\mathrm{F}_{\mathrm{x}}$ bonds at higher energy $(398.6 \mathrm{eV})$.

However, after a $1 \%$ HF wet, the Si surface is as clean as an unprocessed $\mathrm{Si}$ wafer. The RMS is very smooth of $0.1 \mathrm{~nm}$ and with a $R_{\text {max }}$ of $0.8 \mathrm{~nm}$, even compared to the RMS of a pristine SOI wafer that is of $0.3 \mathrm{~nm}$ with a $R_{\max }$ of $2.2 \mathrm{~nm}$. The residues are also all removed as shown by the XPS spectra of Fig. 15(d). We, however, noticed the presence of a new peak on the Si2p spectra at $100.3 \mathrm{eV}$ that we attributed to $\mathrm{Si}_{2} \mathrm{O}$ contribution. ${ }^{48}$ This very small oxidation of the Si surface certainly occurred during the transfer from the HF treatment tool to the ARXPS analysis chamber. The presence of carbon contamination, that is considered to generate defects during epitaxial silicon film grown, ${ }^{49}$ was not yet detected.

Those results prove that the cycling process offers infinite selectivity over Si and is free of damage, which is a mandatory criterion for the spacer etch application. Moreover, the etch process and the etch stop can be accurately monitored by kinetic ellipsometry.

\section{SUMMARY AND CONCLUSIONS}

Etch selectivity is today a key issue to be addressed in the patterning of complex 2D and 3D MOS stacks. The smart etch concept, which is a two-step process combining implantation and removal steps was initially proposed as a method to etch very thin layers with high selectivity. Although promising, the initial proof of concept lacks flexibility because of the use of two separate equipment to achieve the two steps of the process. In this article, we propose a new way to implement the smart etch process, by cycling the two steps of the process in the same plasma reactor chamber, which has the capability to produce both a CCP discharge for the implantation step and a remote plasma discharge for the removal step.

We demonstrate that by cycling the two-step process, it is possible to make a topographically selective etching. The key to success of the concept lies in the existence of an incubation period in the $\mathrm{RP}$ process that can be tuned by functionalizing the surface state with a treatment. The use of plasma implantation, as a treatment step allows us to selectively modify the horizontal surfaces of the material with respect to the vertical surfaces, thanks to the ion directionality, and makes possible the development of topographic selective etching processes.

This concept is proposed for spacer etching process development where $\mathrm{Si}_{3} \mathrm{~N}_{4}$ horizontal surface must be etched with extremely high selectivity over the vertical $\mathrm{Si}_{3} \mathrm{~N}_{4}$ surface (spacer sidewalls) and underlying silicon. For this particular application, a cycling process comprising an $\mathrm{H}_{2}$ or $\mathrm{He}$ plasma implantation (ion energy of about $120 \mathrm{eV}$ ) and a $\mathrm{He} / \mathrm{NH}_{3} / \mathrm{NF}_{3}$ remote plasma process at $100{ }^{\circ} \mathrm{C}$ has been developed.

Etching mechanisms in remote plasma are really complex since they are driven by the molecules that are formed during the diffusion process from the plasma generation region to the substrate region. Gas phase characterizations would be needed to identify the reactive neutrals involved in the mechanisms and to complete a reaction scheme. However, consistent with other studies, our data confirm that the etching of the $\mathrm{Si}_{3} \mathrm{~N}_{4}$ film in $\mathrm{He} /$ $\mathrm{NF}_{3} / \mathrm{NH}_{3} \mathrm{RP}$ proceeds with the formation of $\left(\mathrm{NH}_{4}\right)_{2} \mathrm{SiF}_{6}$ salts. We propose a reaction path for this salt formation on the $\mathrm{Si}_{3} \mathrm{~N}_{4}$ surface in which oxygen plays a key role. $\mathrm{Si}_{3} \mathrm{~N}_{4}$ can be turned into $\left(\mathrm{NH}_{4}\right)_{2} \mathrm{SiF}_{6}$ salt only if the $\mathrm{Si}$ is previously oxidized explaining why the $\mathrm{Si}_{3} \mathrm{~N}_{4}$ etching upon $\mathrm{NH}_{3} / \mathrm{NF}_{3}$ exposure only starts if $\mathrm{Si}-\mathrm{O}$ bonds are present at the $\mathrm{Si}_{3} \mathrm{~N}_{4}$ surface. Once the etching is initiated, the water released by the reaction plays the role of $\mathrm{Si}$ oxidant, which allows the reaction to be pursued.

Thanks to in situ kinetic ellipsometry, we also highlight that there is an incubation time before the salts form and the $\mathrm{Si}_{3} \mathrm{~N}_{4}$ etching starts. This incubation time depends on the surface state and can be modified with surface treatment. For instance, the incubation time on a pristine $\mathrm{Si}_{3} \mathrm{~N}_{4}$ with its native oxide is of $70 \mathrm{~s}$, while it is reduced to $11 \mathrm{~s}$ and $27 \mathrm{~s}$ after $\mathrm{H}_{2}$ and $\mathrm{He}$ implantation, respectively.

Indeed, $\mathrm{He}$ or $\mathrm{H}_{2}$ implantation modifies the SiN surface state by incorporating oxygen contaminants coming from the reactor wall and creating dangling bonds. In the case of $\mathrm{H}_{2}$ implantation, it is likely that $\mathrm{H}$-terminal bonds are also created at the near surface. This functionalization considerably activates the adsorption and reaction of the neutral species generated by the $\mathrm{He} / \mathrm{NH}_{3} / \mathrm{NF}_{3}$ remote plasma and thus reduces the incubation period compared to a pristine $\mathrm{Si}_{3} \mathrm{~N}_{4}$.

By adjusting properly the RP step processing time (typically $30 \mathrm{~s}$ ) of the cycling process, implanted $\mathrm{Si}_{3} \mathrm{~N}_{4}$ surface (horizontal surface) are etched with infinite selectivity over the nonimplanted $\mathrm{Si}_{3} \mathrm{~N}_{4}$ surfaces (vertical surface). The two steps are repeated until 
reaching the targeted $\mathrm{Si}_{3} \mathrm{~N}_{4}$ thickness to be removed. It is also demonstrated that the cycling process can be stopped on the underneath Si surface with infinite selectivity and without introducing surface damage (free of residues or contamination), which is also a key criteria for spacer etching applications.

One weakness of the process is its low etch selectivity over $\mathrm{SiO}_{2}$ films.

Those preliminary results give an overview of how powerful the reactor prototype is for the development of selective etching processes. Remote plasma processes are already known and have been used for their capability to provide highly isotropic etching selectivity, thanks to the chemical and isotropic actions of the neutrals present in the gas phase. But the implementation of this technology in a cycling process alternating a functionalization step and a remote plasma etching step offers a wide variety of selective process development. If topographically selective etching is needed, the functionalization step should involve a treatment step presenting an anisotropic character such as the ion implantation. It should be noted that a multitude of possibilities could be envisaged for the plasma chemistry $\left(\mathrm{O}_{2}, \mathrm{~N}_{2}\right.$, and $\left.\mathrm{CH}_{4}\right)$ used for the implantation as long as no severe sputtering is induced. For instance, we could think of using an $\mathrm{O}_{2}$ implantation to oxidize a material on a well-defined depth and developing a selective RP removal step of the oxide layer over the nonoxidized layer, and cycling those two steps until etching the targeted thickness. One could also imagine that the functionalization step using plasma implantation has an inhibiting effect on the next RP etching, allowing the etching of vertical surfaces selectively over horizontal surfaces.

If chemical selective etching with no preferential direction is needed, the functionalization step should use an isotropic treatment involving neutrals only that could be achieved with the remote plasma unit. We recently proposed such an approach to the isotropic and selective removal of SiGe relative to $\mathrm{Si}$ in order to fabricate horizontal stacked-Si nanowires for Gate All Around devices. ${ }^{50}$

\section{ACKNOWLEDGMENTS}

This work was partly supported by LabEx Minos (No. ANR-10-LABX-55-01) and by the French RENATECH network. The authors would like to acknowledge Applied Materials for their technical support.

\section{REFERENCES}

${ }^{1}$ R. Clark, K. Tapily, K.-H. Yu, T. Hakamata, S. Consiglio, D. O’Meara, C. Wajda, J. Smith, and G. Leusink, APL Mater. 6, 058203 (2018).

${ }^{\mathbf{2}}$ T. Faraz, F. Roozeboom, H. C. M. Knoops, and W. M. M. Kessels, ECS J. Solid State Sci. Technol. 4, N5023 (2015).

${ }^{3}$ K. J. Kanarik, S. Tan, and R. A. Gottscho, J. Phys. Chem. Lett. 9, 4814 (2018).

${ }^{4}$ A. Chaker, C. Vallee, V. Pesce, S. Belahcen, R. Vallat, R. Gassilloud, N. Posseme, M. Bonvalot, and A. Bsiesy, Appl. Phys. Lett. 114, 043101 (2019).

${ }^{5}$ A. J. M. Mackus, M. J. M. Merkx, and W. M. M. Kessels, Chem. Mater. 31, 2 (2019).

${ }^{\mathbf{6}}$ B. E. E. Kastenmeier, P. J. Matsuo, and G. S. Oehrlein, J. Vac. Sci. Technol. A 17, 3179 (1999)

${ }^{7}$ S. Lee, J. Oh, K. Lee, and H. Sohn, J. Vac. Sci. Technol. B 28, 131 (2010).
${ }^{8}$ K. Eriguchi, A. Matsuda, Y. Nakakubo, M. Kamei, H. Ohta, and K. Ono, IEEE Electron Device Lett. 30, 712 (2009).

${ }^{\mathbf{9}}$ R. Blanc, F. Leverd, T. David, and O. Joubert, J. Vac. Sci. Technol. B 31, 051801 (2013).

${ }^{10}$ R. Blanc, F. Leverd, M. Darnon, G. Cunge, S. David, and O. Joubert, J. Vac. Sci. Technol. B 32, 021807 (2014).

${ }^{11}$ C. Petit-Etienne, E. Pargon, S. David, M. Darnon, L. Vallier, O. Joubert, and S. Banna, J. Vac. Sci. Technol. B 30, 040604 (2012).

${ }^{12}$ C. Petit-Etienne, M. Darnon, L. Vallier, E. Pargon, G. Cunge, F. Boulard, O. Joubert, S. Banna, and T. Lill, J. Vac. Sci. Technol. B 28, 926 (2010).

${ }^{13}$ N. Posseme, O. Joubert, and L. Vallier, U.S. patent 9,570,317 B2 (December 20, 2013).

${ }^{14}$ N. Posseme, O. Pollet, and S. Barnola, Appl. Phys. Lett. 105, 051605 (2014).

${ }^{15}$ O. Pollet, N. Possémé, V. Ah-Leung, and M. Garcia Barros, Solid State Phenom. 255, 69 (2016).

${ }^{16}$ V. Ah-Leung, O. Pollet, N. Possémé, M. Garcia Barros, N. Rochat, C. Guedj, G. Audoit, and S. Barnola, J. Vac. Sci. Technol. A 35, 021408 (2017).

${ }^{17}$ N. Posseme, V. Ah-Leung, O. Pollet, C. Arvet, and M. Garcia-Barros, J. Vac. Sci. Technol. A 34, 061301 (2016).

${ }^{18}$ H. Nishino, N. Hayasaka, and H. Okano, J. Appl. Phys. 74, 1345 (1993).

${ }^{19}$ S. D. Sherpa and A. Ranjan, J. Vac. Sci. Technol. A 35, 01 A102 (2017).

${ }^{20}$ S. D. Sherpa, P. L. G. Ventzek, and A. Ranjan, J. Vac. Sci. Technol. A 35, 05C310 (2017).

${ }^{21}$ V. Martirosyan, E. Despiau-Pujo, J. Dubois, G. Cunge, and O. Joubert, J. Vac. Sci. Technol. A 36, 041301 (2018).

${ }^{22}$ P. J. Cumpson, J. Electron Spectrosc. Relat. Phenom. 73, 25 (1995).

${ }^{23}$ H. Ogawa, T. Arai, M. Yanagisawa, T. Ichiki, and Y. Horiike, Jpn. J. Appl. Phys. 41, 5349 (2002).

${ }^{\mathbf{2 4}}$ A. Tavernier, L. Favennec, T. Chevolleau, and V. Jousseaume, ECS Trans. 45, 225 (2012).

${ }^{25}$ H. J. Oh, J. H. Lee, M. S. Lee, W. G. Shin, S. Y. Kang, G. D. Kim, and D. H. Ko, ECS Trans. 61, 1 (2014).

${ }^{26}$ A. R. Forouhi and I. Bloomer, Phys. Rev. B 34, 7018 (1986).

27J. G. E. Gardeniers, H. A. C. Tilmans, and C. C. G. Visser, J. Vac. Sci. Technol. A 14, 2879 (1996).

${ }^{28}$ J. F. Ziegler, The Stopping and Range of Ions in Solids (Pergamon Press, New York, 1985).

${ }^{29}$ M. Bizouerne, E. Pargon, C. Petit-Etienne, S. Labau, S. David, M. Martin, and P. Burtin, J. Vac. Sci. Technol. A 36, 061305 (2018).

${ }^{30}$ See https://physics.nist.gov/physrefdata/ASD/ionenergy.html for ionization energy for He I and O I.

${ }^{31}$ K. Suzuki, R. Sudo, and T. Feudel, Solid State Electron. 42, 463 (1998).

${ }^{32}$ J. F. Gibbons and S. Mylroie, Appl. Phys. Lett. 22, 568 (1973).

${ }^{33}$ M. J. Kushner, J. Appl. Phys. 58, 4024 (1985).

${ }^{34} \mathrm{~V}$. Martirosyan, "Atomistic simulations of $\mathrm{H}_{2}$ and He plasmas modification of thin-films materials for advanced etch processes," Ph.D. dissertation (UGA, 2017). See https://tel.archives-ouvertes.fr/tel-01803013.

${ }^{35}$ T. Hayashi, K. Ishikawa, M. Sekine, M. Hori, A. Kono, and K. Suu, Jpn. J. Appl. Phys. 51, 016201 (2012).

${ }^{36}$ W. R. Knolle and R. D. Huttemann, ECS J. Solid State Sci. Technol. 135, 2574 (1988).

${ }^{37}$ D. L. Flamm, Pure Appl. Chem. 62, 1709 (1990).

${ }^{38}$ G. Ehrlich, J. Phys. Chem. 59, 473 (1955).

${ }^{39}$ J. A. Becker and C. D. Hartman, J. Phys. Chem. 57, 153 (1953).

${ }^{40}$ D. M. Knotter, J. Am. Chem. Soc. 122, 4345 (2000).

${ }^{41}$ D. M. Knotter and T. J. J. D. Denteneer, J. Electrochem. Soc. 148, F43 (2001).

${ }^{42}$ W.-H. Kim, F. S. Minaye Hashemi, A. J. M. Mackus, J. Singh, Y. Kim, D. Bobb-Semple, Y. Fan, T. Kaufman-Osborn, L. Godet, and S. F. Bent, ACS Nano 10, 4451 (2016).

${ }^{43}$ F. S. Minaye Hashemi, B. R. Birchansky, and S. F. Bent, ACS Appl. Mater. Interfaces 8, 33264 (2016).

${ }^{44}$ M. Leskelä and M. Ritala, Angew. Chem. Int. Ed. 42, 5548 (2003). 
${ }^{45}$ B. A. Thedjoisworo, D. Cheung, and D. Zamani, J. Vac. Sci. Technol. A 30, 031303 (2012).

${ }^{46}$ Z. Donkó, A. Derzsi, M. Vass, J. Schulze, E. Schuengel, and S. Hamaguchi, Plasma Sources Sci. Technol. 27, 104008 (2018).

${ }^{47}$ S. Kumakura, M. Tabata, and M. Honda, Jpn. J. Appl. Phys. 58, SEEB01 (2019).
${ }^{48}$ R. Alfonsetti, L. Lozzi, M. Passacantando, P. Picozzi, and S. Santucci, Appl. Surf. Sci. 70-71, 222 (1993).

${ }^{49}$ S. Sato, I. Mizushima, K. Miyano, T. Sato, S. Nakamura, Y. Tsunashima, T. Arikado, and N. Uchitomi, Jpn. J. Appl. Phys. 44, 1169 (2005).

${ }^{50}$ E. Pargon, C. Petit-Etienne, L. Youssef, G. Thomachot, and S. David, J. Vac. Sci. Technol. A 37, 040601 (2019). 